\title{
UTILIZAÇÃO DE RESÍDUOS SÓLIDOS DESIDRATADOS DE EFLUENTE DE BIODIGESTOR ORIUNDOS DE ESTERCO DE GALINHAS MATRIZES E VACAS EM LACTAÇÃO NA ALIMENTAÇÃO DE FRANGOS DE CORTE
}

\author{
ACRÍSIO DE MIRANDA SAMPAIO \\ Engenheiro Agrônomo
}

Orientador: Prof. Dr. ROBERTO DIAS DE MORAES E SILVA

Dissertação apresentada à Escola Superior de Agricultura "Luiz de Queiroz", da Universidade de São Paulo, para obtenção do título de Mestre em Agronomia - Área de Concentração: Nutrição Animal $\theta$ Pastagens.

PIRACICABA

Estado de São Paulo - Brasil

Julho - 1984 
Ao meu pai Aluísio e minha mae Angelita, DEDICO .

A minha esposa Teresa e aos meus filhos Leonardo e Marcela, OFEREÇO. 
.iii.

\section{AGRADECIMENTO ESPECIAL}

Ao professor Dr. ROBERTO DIAS DE MORAES E SILVA,

a quem devemos dedicação, colaboração e segura orientação deste trabalho. 


\section{AGRADECIMENTOS}

A Fundação Universidade Federal do Pịauí, na pessoa do Magnífico Reitor Dr. LINEU DA COSTA ARAOJO, por possibilitar a nossa participação no curso de Pós-Graduação.

Ao professor ANTONIO MANOEL CASTELO BRANCO FILHO, Diretor do Centro de Ciências Agrárias da Fundação Univer sidade Federal do Piauí, pelo incentivo e apoio à nossa participação no Curso de Pós-Graduação.

Aos professores Dr. IRINEU UMBERTO PACKER, da Escola Superior de Agricultura "Luiz de Queiroz", da Universidade de São Paulo, e LUIZ EVALDO DE MOURA PADUA, da Fundação U niversidade Federal do Piauí, pela orientação e auxilio na aná lise estatística.

Ao Departamento de Zootecnia da Escola Superior de Agricultura "Luiz de Queiroz", da Universidade de São Pau10 .

A Coordenação de Aperfeiçoamento de Pessoal de Ensino Superior (CAPES), do Ministério da Educação e Cultura, através do Programa Institucional de Capacitação de Docentes (PICD), na Fundação Universidade Federal do Piauí, por nos ter concedido bolsa de estudo. 
A "BRASmetano teCnOlogias InTEgRadAS" nas pessoas dos Engọs Agrọs JOSE MARCOS BORGES GRŸSCHEK e FRANKLIN ROSA BELO, pelo preparo do ingrediente testado neste trabalho.

A Cooperativa Agro-Pecuária "Holambra", na pessoa do Méd. Vet. GODOFREDO MILTENBURG, pela facilidade no fornecimento dos pintos e parte dos ingredientes alimentares.

Aos colegas do curso de Pós-Graduação e em especial LUIZ EDIVALDO PEZZATO, CINIRO COSTA, ANTONIO FERNANDO BER GAMASCHINE e ANA REGINA TECHIATTI FAZANO, pelo espírito de solidariedade e companheirismo.

Ao funcionário ELIZEU POLI, da Escola Superior de Agricultura "Luiz de Queiroz", pela dedicação no manejo das aves. 


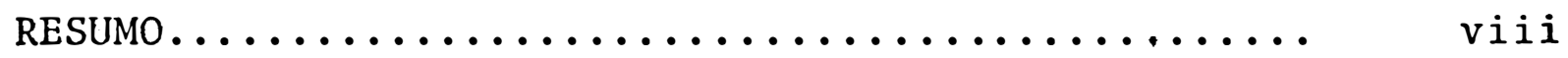

SUMMARY $\ldots \ldots \ldots \ldots \ldots \ldots \ldots \ldots \ldots \ldots \ldots \ldots \ldots \ldots \ldots \ldots \ldots \ldots \ldots$

1. INTRODUÇAO........................ 1

2. REVisAo DE Literatura................... 4

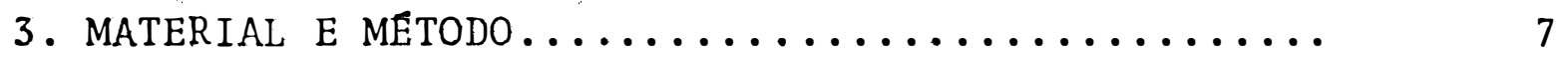

3.1. Equipamentos utilizados para o processamento dos residuos..................... 7

3.2. Processamento dos residuos............. 9

3.3. Instalações e equipamentos experimentais.... 10

3.4. Periodos experimentais............... 12

3.5. Aves experimentais................. 13

3.6. Manejo das aves................... 13

3.7. As rações experimentais............... 15

3.8. Dados coletados................... 24

3.8.1. Ganho médio de peso............. 24

3.8.2. Consumo médio de ração........... 24

3.8.3. Mortalidade................. 24

3.8.4. Conversão alimentar média........ 25

3.9. Delineamento experimental............ 25

4. RESUlTAdOS E DISCUSSAO................. 27

4.1. Ganho médio de peso do 19 ao 26 dia de ida-

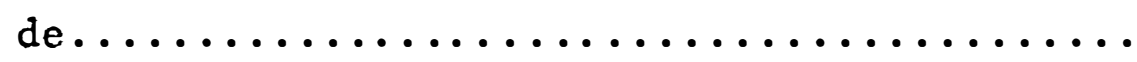


.vii.

Página

4.2. Conversão alimentar média do 19 ao 260 "dia

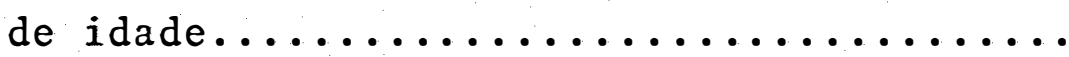

4.3. Ganho médio de peso e conversão alimentar média para os periodos compreendidos entre os dias 27 a 47 e 1 a 47 do experimento...

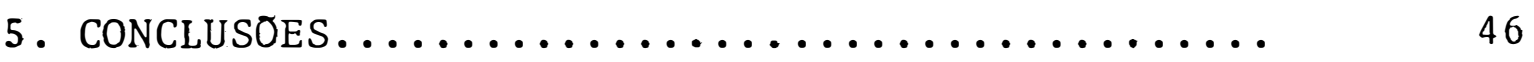

6. LITERATURA CITADA...................... 48

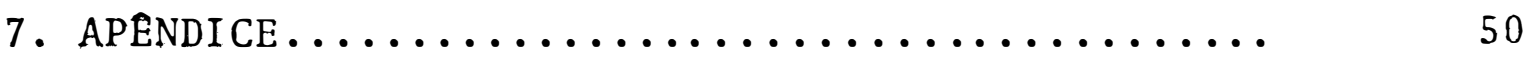


.viii.

\section{INDICE DE TABELAS}

Tabela

Página

1 Análise química dos resíduos sólidos desidrata dos de efluente de biodigestor, fósforo dispo-

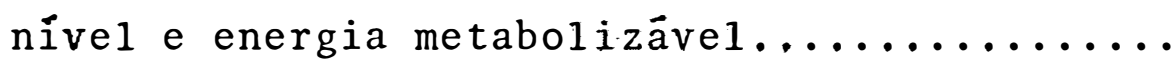

2 Aminograma dos resíduos sólidos desidratados de

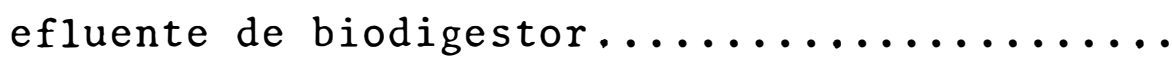

3 Resultados analíticos dos ingredientes utiliza dos nas rações experimentais............. 18

4 Consumo médio de ração ( 1 a 26 dias), $k g . . .$.

5 Consumo médio de ração (27 a 47 dias), $k g \ldots$.

6 Consumo médio de ração ( 1 a 47 dias de idade).

7 Ganho médio de peso ( 1 a 26 dias de idade),

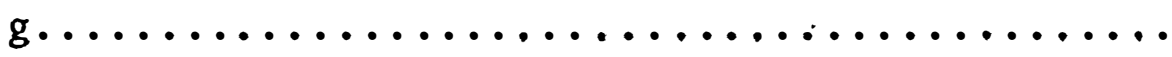

8 Conversão alimentar média ( 1 a 26 dias de idade $), k g / k g \ldots \ldots \ldots \ldots \ldots \ldots \ldots \ldots \ldots$

9 Ganho médio de peso (27 a 47 dias de idade), kg.. 
.ix.

Tabela

Página

10 Ganho médio de peso ( 1 a 47 dias de idade), $\mathrm{kg} .$. 58

11 Conversão alimentar média (27 a 47 dias de ida de $), k g / k g . \ldots \ldots \ldots \ldots \ldots \ldots \ldots \ldots \ldots$

12 Conversão alimentar média (1 a 47 dias de idade $), k g / k g \ldots \ldots \ldots \ldots \ldots \ldots \ldots \ldots \ldots$ 


\section{INDICE DE QUADROS}

Quadro

1 Composição porcentual e nutritiva das rações i

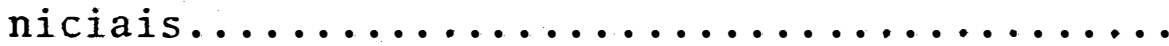

2 Composição porcentual e nutritiva das rações fi

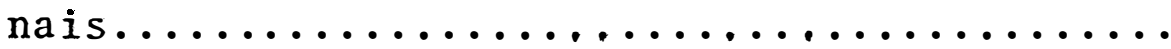

3 Suplementação vitamínico-mineral e aditivos por

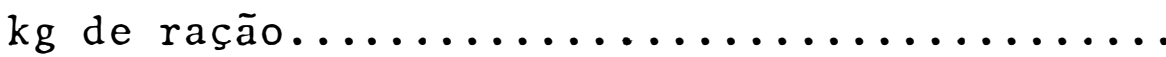

4 Ganho médio de peso ( 1 a 26 dias de idade)....

5 Anālise de variância dos dados referentes ao ganho médio de peso e conversão alimentar média, no período de 1 a 26 dias de idacie......

6 Conversão alimentar média (19 ao 26! dia de idade $\ldots \ldots \ldots \ldots \ldots \ldots \ldots \ldots \ldots \ldots \ldots \ldots \ldots \ldots$

7 Anālise de variância dos dados referentes a gạ nho médio de peso e conversão alimentar média, no período de 27 a 47 dias de idade das aves... 
. xi.

Quadro

Pāgina

8 Anālise de variância dos dados referentes a ga nho mẻdio de peso e conversão alimentar média, no período de 1 a 47 dias de idade das aves.....

9 Mortalidade durante os 47 dias do experimento

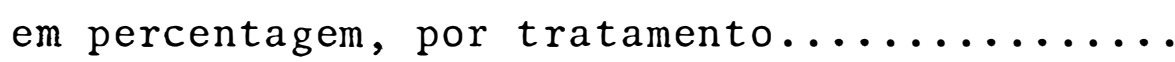

10 Ganho médio de peso (27 a 47 dias de idade)...

11 Ganho médios de peso ( 1 a 47 dias de idade)....

12. Conversão alimentar média (27 a 47 dias de ida

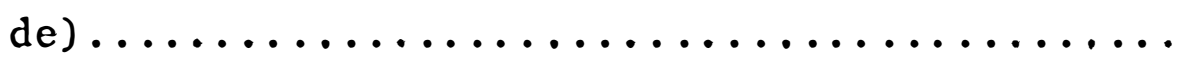

13 Conversão alimentar média (19 a 479 dia de ida

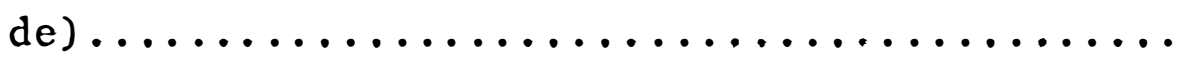


.xii.

\section{INDICE DE GRÁFICOS}

Grāfico

Pāgina

1 Temperaturas ambientais registradas no decor-

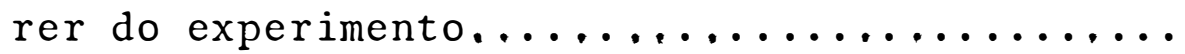

2 Conversões alimentares médias das aves alimentadas com as rações experimentais no período de 1 a 26 dias de idade $(\mathrm{kg} / \mathrm{kg}) \ldots \ldots \ldots \ldots \ldots$

3 Equação de regressão linear e coeficiente de correlação para conversão alimentar média das aves quando verificado niveis dentro de resíduo sólido desidratado de efluente de biodiges tor, oriundo de esterco de galinhas matrizes... 


\author{
UTILIZAÇ̃̃O DE RESÍDUOS SÓLIDOS DESIDRATADOS DE \\ EFLUENTE DE BIODIGESTOR ORIUNDOS DE ESTERCO \\ DE GALINHAS MATRIZES E VACAS EM LACTACÃO \\ NA ALIMENTACÃO DE FRANGOS DE CORTE
}
ACRISIO DE MIRANDA SAMPAIO
- AUTOR -

\begin{abstract}
DR. ROBERTO DIAS DE MORAES E SILVA
- ORIENTADOR -
\end{abstract}

\title{
RESUMO
}

o presente experimento foi conduzjdo no Setor de Avicultura do Departamento de Zootecnia da Escoli Superior de Agricultura "Luiz de Queiroz", em Piracicaba, Estado de São Paulo, com a finalidade de avaliar a utilização de resíduos sólidos desidratados de efluente de biodigestor oriundos de ester co de galinhas matrizes e vacas em lactação, no desempenho de frangos de corte, com 4 niveis de inclusão $(0,3,6$ e $9 \%$ ) nas ra ções experimentais. Foram utilizados 728 pintos sexados de um dia da linhagem "Hubbard", sendo 364 machos e 364 fêmeas, a1ojando-se 26 pintos do mesmo sexo por cada divisão de criação, a qual continha maravalha como material de "cama". O delineamento experimental utilizado foi inteiramente casualizado com 7 trata 
.xiv.

mentos e 4 repetições, as quais eram compostas por 2 lotes de machos e 2 lotes de fêmeas. Foram utilizados dois tipos de rações, uma para o período inicial com 2900 kcal de energia metabolizável por quilo e $22 \%$ de proteína bruta, e outra para o perío do final com $2970 \mathrm{kcal}$ de energia metabolizável por quilo e $20 \%$ de proteina bruta. As rações experimentais dentro de um mesmo periodo eram, tanto quanto possível, isocalóricas e isoprotéicas.

$\mathrm{Na}$ análise estatistica dos resultados para o 1 ? período de criação ( 1 a 26 dias de idade), ocorreram diferenças estatisticamente significativas tanto para ganho médio de peso como para conversão alimentar mẻdia, sendo observado porém, que as diferenças estatisticamente significativas para ganho médio de peso, ocorreram em virtude de uma falha experimental, onde somente as aves alimentadas com ração contendo $3 \%$ de resíduo só lido desidratado de efluente de biodigestor oriundo de esterco de bovinos, diferiram estatisticamente das demais, com um menor ganho médio de peso. Para conversão alimentar média foram obser vadas diferenças estatisticamente significativas entre as aves alimentadas com as rações experimentais, ficando a ração basal $(0 \%$ de ingrediente teste) com a melhor conversão alimentar mēdia. Observou-se, no entanto, que dentro do mesmo material, a conversão alimentar média picrou à medida que aumentou a inclusão do ingrediente testado. Verificou-se, também, tendēncias de superioridade do material provindo de esterco de vacas em lacta ção em relação ao material oriundo de esterco de galinhas matri 
zes, tanto para as médias do ganho médio de peso como para as médias da conversão alimentar média, apesar das diferenças não terem diferido estatisticamente entre si.

Para os outros dois períodos analisados (27 a 47 dias de idade e 1 a 47 dias de idade), não foram observadas diferenças estatisticamente significativas para os parâmetros ana lisados, com exceção do ganho médio de peso entre sexos, fato o qual era já esperado.

Concluiu-se no presente experimento que o nível máximo de inclusão dos resíduos aconselhado seria de 6\% da ração, no período final de criação. Foi observado também, que o esterco de bovinos apresentam médias superiores de desempenho das aves, em relação às obtidas com o esterco de aves, apesar das diferenças não terem sido estatisticamente significativas. 


\section{DEHYDRATED POULTRY AND CATTLE WASTE \\ FROM BIODIGESTER AS FEEDSTUFF \\ FOR BROILER CHICKS}

ACRÍSIO DE MIRANDA SAMPAIO

- AUTHOR -

DR. ROBERTO DIAS DE MORAES E SILVA

- ADVISER -

\section{SUMMARY}

This experiment was conducted to evaluate the effects of four dietary levels $(0,3,6$ and $9 \%$ of each solid by-product, from poultry and cattle waste digester, upon broiler performance. Seven hundred and twenty-eigth "Hubbard" day-old broiler chicks (364 males and 364 females) were distributed at random to 28 lots, each consisting of 26 birds of the same sex. The experimental design was completely randomized with 7 treatments and 4 replications which consisted of 2 male and 2 female lots.

Two different types of diets were formulated, one for the starter period with the Metabolizable Energy (ME) and crude protein (CP) contents of $2,900 \mathrm{kcal} / \mathrm{kg}$ and $22 \%$, 
respectively, and another for the final period with $\mathrm{ME}$ and $\mathrm{CP}$ contents of $2,970 \mathrm{kcal} / \mathrm{kg}$ and $20 \%$, respectively.

The analysis of variance for the first period ( 1 to 26 days of age) revealed significant differences $(P<0.05)$ for both average weigth gain and feed conversion. Although the differences in average weight gain were caused by an experimental error, i.e., only the broilers fed the experimental ration containing $3 \%$ of solid by-product from cattle waste digester differed from the others showing the lowest average weigth gain. There were significant differences in feed conversion among the birds fed the different types of rations and the best feed conversion was obtained with the basal ration $(0 \%$ of test. ingredient). The efficiency of feed conversion decreased as each individual by-product was added to the diet. It was also found the superiority of solid by-product from cattle waste digester compared to solid by-product from poultry waste digester, either for average weigth gain (787.3 $\times 757.9)$ or for feed conversion $(1.71 \times 1.72)$, although an analysis of variance showed no significant differences (P>0.05) between them.

Except for average weigth gain between sexes the analysis of variance showed no significant differences in average weigth gain and feed conversion during the other experimental periods ( 27 to 47 and 1 to 47 day-old).

In the present wotk, it was concluded that the maximum level of inclusion of the waste digester would be $6 \%$ 
of the total ration during the final period. It was also concluded that dehydrated cattle waste presented better growth performance in the experimental birds than dehydrated poultry waste although the analysis of variance showed no significant differences $(P<0.05)$ between them. 


\section{INTRODUCÃO}

Face à grande crise energética que assola todo o mundo nos tempos de hoje, a energia das chamadas fontes convencionais vem se tornando cara e escassa nos mais diversos meios consumidores como cidades, indústrias e no campo.

E sabido que milhares de toneladas de resíduos orgânicos se acumulam ao redor de centros urbanos, agroindústrias e confinamentos de animais, tornando tais residuos fontes de poluição ambiental. Esses resíduos, se submetidos a uma adequada fermentação na ausência de oxigênio, representam gran de potencial de energia na forma de gás metano, cuja utilização, em média e grande escala, promoveria substituição signifi cativa dos derivados de petróleo (gasolina, diesel, querosene, GLP, BPF, etc.) e energia elétrica, além de auxiliar o combate à poluição ambiental tão discutida nos dias de hoje.

A digestão anaerōbia de resíduos orgânicos é co 
nhecida hà muito tempo, e sua primeira aplicação em grande escala data de 1895 na Inglaterra, para a iluminação de ruas. No entanto, não só a obtenção de energia a partir dos resíduos or gânicos na forma de gás metano, justificaria a utilização de tal processo, mas tambēn deve ser considerada a melhoria da qualidade do resíduo obtido, podendo ser aplicado com sucesso na lavoura, na alimentação de peixes, bem como, na suplementação alimentar de outras espécies animais.

A implantação de biodigestor no Brasil e na Amé rica Latina data de pouco tempo,pois somente em novembro de 1979 foi instalado, na residência oficial da Presidência da República (Granja do Torto), pela EMATER do Distrito Federal, o primeiro biodigestor destinado a testes oficiais, embora a Chi na e a India já possuam a tecnologia há muito tempo (SILVA, 1980).

Segundo dados da EMBRATER, em 31 de dezembro de 1983 a quantidade de biodigestores instalados no Brasil era a se. guinte: 1828 biodigestores do tipo indiano, 376 do tipo chinês, 09 do tipo batelada e 339 de outros tipos, totalizando portanto 2.552 biodigestores (SILVA, 1984).

Fazendo-se uma estimativa de 11 milhões de aves matrizes, 1 bilhão de frangos de corte e uma produção de 700 milhões de dúzias de ovos, por ano, conclui-se que somente a produção de esterco de aves no Brasil por ano, ëde aproximadamen te 2 milhões de toneladas, o que representaria um grande poten cial para produção de metano, bem como, para o aproveitamento 
do subproduto na alimentação animal.

Devido ã importância dessa fonte barata de ene $\underline{r}$ gia, vãrios projetos estão em andamento no Brasil como o proje to que vem sendo desenvolvido pela Prefeitura de São Paulo, on de o gás metano produzido a partir do lixo da capital, ē utili zado em ônibus coletivos da linha CEASA-LAPA da CMTC.

Um outro projeto para produção de gās metano a partir de lixo e esgoto, já operando, ẽ o da Prefeitura de Piraí do Sul, no Paraná, o qual com uma população de cerca de 10.000 habitantes, pretende ao final do projeto substituir todo o GLP utilizado na cidade por gäs metano oriundo da usina biodigestora de lixo e esgoto.

Também no meio rural, jả encontram-se projetos em vias de funcionamento, como os projetos elaborados pela "BRASMETANO TECNOLCGIAS INTEGRADAS", para a Granja Mizumoto, em Assis, São Paulo, e Fazenda Progresso em Frutal, Minas Gerais, onde o primeiro utilizará como matéria-prima ester co de aves e o segundo capim marmelada encontrado nas entrelinhas do pomar de citros.

0 presente trabalho teve como objetivo, avaliar a inclusão de três níveis (3, 6 e $9 \%$ ) de resíduo sólido desidratado de efluente de biodigestor, provindos de esterco de ga linhas matrizes criadas em gaiolas e vacas em lactação, contra uma testemunha, na alimentação de frangos e seus efeitos no ga nho de peso, conversão alimentar, consumo de ração e mortalidade. 
.4 .

\section{REVISÃO DE LITERATURA}

AZEVEDO e BELO (1984), avaliando o gås metano como substituto dos combustiveis convencionais na agricultura, mostraram que o processo de produção de gás metano, quando com parado ao processo de produção de álcool etílico, a partir das mesmas matérias-primas - cana-de-açúcar e mandioca - apresentou boas perspectivas do ponto de vista de produção potencial de e nergia; no caso da cana-de-açúcar, a quantidade produzida de $\underline{e}$ nergia - nas formas de gás metano e ālcool etỉlico - foi bastante semelhante; no caso da mandioca, entretanto, o processo de produção de gás metano levou vantagem, visto que, além das raízes, utilizou também as ramas desta cultura. Estendidas as comparações dos processos às características de produção, arma zenamento e uso do produto, os autores verificaram que a produ ção de biogás levou vantagens sobre a produção de álcool quanto à flexibilidade de uso de diferentes matérias-primas, quan- 
to à facilidade de supervisão dos processos de fermentação, ex tração, e purificação do produto final, além de uma possibilidade de uso mais eficiente do combustível produzido e de um po tencial de poluição mais baixo de seus efluentes. Por outro la do, a dificuldade de armazenamento do gás metano pode ser caracterizada como uma das grandes desvantagens do processo. Os mesmo autores mostraram que num estabelecimento agrícola que pretende usar a cobertura vegetal das entregalinhas de seu pomar de laranjeiras para a produção de gás metano eqüivalente a $500 \ell$ de óleo diesel por dia - demonstrou boas perspectivas sob os pontos de vista analisados: apresentou uma taxa interna de retorno médio de $33,45 \%$ e uma probabilidade de $100 \%$ desta estar acima de $20 \%$ em uma análise que levou em conta o risco. Ressaltaram, porém, que dadas as características peculiares que podiam estar associadas às diferentes matérias-primas utilizadas no processo de produção de gás metano, justificava - se uma análise detalhada de cada situação específica apesar dos resultados relativamente promissores obtidos no estudo realiza do.

YOSHIDA e HOSHII (1978), verificando o valor nu tritivo do resíduo de fermentação provindo de esterco de porco e aves, concluíram que a energia metabolizável para ambos os materiais era nula, e o (GPV) valor de proteina bruta para sui nos foi de $38 \%$ e nulo para aves.

Sobre o uso de residuos de efluente de biodigestor na alimentação animal, não foi encontrado trabalho al- 
gum na literatura nacional, devido, talves, a que o próprio em prego do biodigestor em nosso meio é de introdução recente, e o fato ao qual o resíduo de fermentação tenha sido usado mais como biofertilizante do que como alimento para animais. 


\section{MATERIAL E MÉTODO}

Os resíduos sólidos desidratados de efluente de biodigestor foram preparados na Escola Superior de Agricultura "Luiz de Queiroz", Setor de Mecânica, em biodigestor pertencente à "Brasmetano Tecnologias Integradas", no município de Piracicaba, Estado de São Paulo, no período de junho de 1983 a outu bro de 1983.

\subsection{EQUIPAMENTOS UTILIZADOS PARA O PROCESSAMENTO DOS RESI- DUOS}

O biodigestor utilizado para o processamento dos estercos de aves e bovinos, faz parte de um sistema gerador de metano, que tem por objetivo avaliar o processo de fermentação da matéria orgânica sob os aspectos físico, químico, bioquímico emicrobio- 
lógico, possibilitando o estudo individual de cada tipo de matē ria-prima utilizada na produção de metano, bem como, a avalia ção quantitativa e qualitativa do gās produzido.

Portanto, o sistema gerador de metano era composto basicamente de um tanque em aço carbono com capacidade pa ra 25.000 1itros (fermentador), isolado termicamente com duas camadas externas de 1ã de vidro PI-120. Na parte superior deste tanque, encontrava-se instalado um painel solar com $12 \mathrm{~m}^{2}$ de área, o qual estava acoplado a uma serpentina de aquecimento da massa em fermentação.

Para evitar a interrupção da fermentação nos dias frios e sem sol, encontrava-se um outro sistema de aquecimento funcionando. à base de metano, também acoplado à uma segun da serpentina de aquecimento da massa em fermentação.

Tambēm um segundo tanque em aço carbono com capacidade para 2.000 e e pressão de até $20 \mathrm{~kg} / \mathrm{cm}^{2}$, para armazenamento de gás, compunha o sistema.

Como acessórios, o sistemạ possuía ainda um com pressor com capacidade até $20 \mathrm{~kg} / \mathrm{cm}^{2}$ acoplado a um motor funcio nando a metano, e uma bomba para alimentação do fermentador, tam bèm acionada por um motor de combustão interna a metano.

Todo este sistema estava montado sobre uma carreta com 2,55 metros de largura por 11 metros de comprimento, o que possibilitava o seu deslocamento para diferentes regiōes com a finalidade de pesquisa e demonstração.

Para desidratação do efluente de biodigestor, foi 
utilizada uma estufa com circulação forçada de ar, pertencente ao Departamento de Zootecnia da Escola Superior de Agricultura "Luiz de Queiroz".

\subsection{Processamento dos Res f́duos}

Foram utilizados dois tipos de estercos: de galinhas matrizes criadas em gaiolas e de vacas em lactação.

0 fermentador foi esvaziado e mantido apenas 1000 1itros de inóculo. Em seguida foi adicionado o esterco fres co de galinhas matrizes, isento de penas e materiais grosseiros, com uma diluição feita de maneira que a concentração de sólidos totais ficasse em torno de $3 \%$. O material permaneceu no fermentador até que se mostrasse relativamente estabilizado com uma concentração em torno de $50 \mathrm{mg}$ de ácidos orgânicos por litro, e uma correspondente redução da (DQO) - Demanda Química de Oxigênio - em torno de $95 \%$, o que aconteceu em aproximadamente 60 dias.

0 mesmo procedimento foi mantido para o esterco fresco de vacas em lactação, diferindo apenas na concentração de sólidos tớtais que ficou em torno de $10 \%$.

Em ambos os casos, o gảs produzido não foi analisado.

Apōs a estabilização do processo, o material foi retirado ainda na forma líquida, e levado a um terreiro de se- 
cagem de grãos colocado sobre filme de polietileno preto na forma de tanque com profundidade de aproximadamente $20 \mathrm{~cm}$, e aí permaneceu exposto ao sol até que tomasse consistência sólí da.

Feita a secagem ao sol, o material foi triturado em moinho de martelo e levado a uma estufa de circulação forçada de ar para que a umidade ficasse abaixo de $10 \%$, quando en tão estaria pronto a ser incorporado às rações experimentais.

Foi feita homogeneização individual dos dois ma teriais, quando então foram retiradas amostras para análise la boratorial.

\subsection{INSTALACÕES E EQUIPAMENTOS EXPERIMENTAIS}

0 experimento foi realizado no Setor de Avicultura do Departamento de Zootecnia da Escola Superior de Agricultura "Luiz de Queiroz", em Piracicaba, Fstado de São Paulo, no período compreendido entre 02 de março a 18 de abril de 1984, em galinheiro experimental equipado especialmente para pesquisas com frango de corte.

0 galinheiro, com dimensões de 32 metros de com primento por 8 metros de largura, possuía mureta lateral de a 1 venaria de tijolos com 0,60 metros de altura, completada com tela de arame de $1 / 2 \times 3 / 4$ de polegada de malha, com piso de cimento, oitões de alvenaria com portas de acesso em cada face e 
com cobertura de telhas de barro tipo francesa. As laterais do galinheiro eram providas de cortinado confeccionado em fibras de polietileno que se fechava no sentido de baixo para cima. In ternamente o galinheiro era constituído por três fileiras de boxes de criação distribuídas no sentido longitudinal com 10 boxes em cada, separadas por dois corredores de 1,0 metro de largura. Os boxes de criação com dimensões de $2,0 \times 2,5$ metros eram separados por tābuas de 0,3 metros de altura e completados por tela de arame de 2,0 polegadas de malha até a altura de 2,0 metros. Cada boxe possuía uma porta de acesso para o corredor. Em ambas as extremidades do galinheiro havia uma área de $3,5 \times 8,0$ metros para armazenamento das rações experimentais e pesagem das aves.

Colocado num dos oitões junto ao primeiro boxe da fileira do méio, à altura de 0,20 metros do piso, encontra va•se um termômetro para medição da temperatura ambiente.

A iluminação artificial do galinheiro foi efeti vada por meio de uma linha central com 11 lâmpadas incandescentes de 60 watts cada a 2,30 metros de altura do piso.

0 aquecimento dos pintos foi realizado através de lâmpadas infravermelhas de $250 \mathrm{~W}$ cada, contendo refletor, co locada a 0,60 metros do piso e com uma unidade por divisão de criação.

En cada divisão foi utilizado um bebedouro do tipo pendular com válvula para liberação de ägua proveniente de uma tubulação aérea, o que possibilitou a automatização do sís 
tema.

A alimentação durante a primeira semana de vida dos pintos foi fornecida em bandejas de plástico com dimensões $.0,55 \times 0,35 \times 0,05 \mathrm{~m}$ e $\mathrm{j} \overline{\mathrm{a}}$ no segundo dia os comedouros do tipo penduIar com capacidade para $25 \mathrm{~kg}$ foram colocados nos boxes de cria ção, para que as aves se ambientassem, passando a serem utilizados a partir da segunda semana, sendo colocadas uma bandeja e um comedouro em cada divisão de criação.

A "cama" utilizada no período de criação foi ma ravalha, a qual quando molhada acidentalmente era prontamente substituida por material seco.

\subsection{Períodos experimentais}

Estava prevista a duração de 49 dias para o experimento, sendo considerado o período compreendido entre 1 a 28 dias de idade das aves a fase inicial, e o periodo comprendido entre 29 a 49 dias de idade a fase final, porem, por pro blemas alheios à vontade do Autor, o periodo experimental foi reduzido para 47 dias, ficando a fase inicial compreendida entre os dias 1 e 26 e a fase final compreendida entre os dias 27 e 47 do experimento. 


\subsection{AVES EXPERIMENTAIS}

Foram utilizados 728 pintos de um dia, da linha gem "Hubbard", procedentes da Cooperativa Agro-Pecuária Holambra, Jaguariūna, São Paulo, sendo 364 machos e 364 fêmeas, autossexados no próprio incubatório pelo crescimento das penas das asas de acordo com (SEX-SEPARATE broiler..., 1983). Os pintos foram vacinados no incubatório contra a doença de Marek.

\subsection{Manejo das aves}

Antes da entrada dos pintos, as Iâmpadas de aquecimento foram reguladas à altura de 0,60 metros do piso, e os bebedouros testados quanto ao seu adequado funcionamento. Apōs a chegada dos pintos, os mesmos foram sepa rados em 28 lotes, sendo 14 lotes de machos e 14 lotes de fëmeas, constituindo cada lote uma parcela experimental com $26 \underline{\text { a }}$ ves.

As divisões de criação foram numeradas de 1 a 30, sendo excluídos do experimento os boxes 1 e 21 , que recebe ram pintos chamados de "reserva" para reposição na primeira se mana, caso se tornasse necessário.

A distribuição foi feita através de sorteio ao acaso, onde se procedia a pesagem de cada lote de acordo com o sorteio da divisão, do tratamento e do sexo. 
As aves receberam aquecimento por 24 horas diārias durante os 17 primeiros dias. A partir do 189 dia de idade as lâmpadas de aquecimento eram desligadas às 10 horas e re 1 igadas às 16 horas de cada dia, até o 28 ̣ dia de idade dos pintos. Dessa idade em diante a fonte de aquecimento foi retirada.

A temperatura ambiente do galinheiro era registrada pela manhã e à tarde de cada dia, nos horārios de 9:00 h e 15:00 h como mostra o Grāfico 1 do Apêndice.

No décimo dia de idade foi administrada a vacina contra New Castle, na água de beber, e repetida no 320 dia de idade dos pintos.

Os bebedouros eram lavados pela manhã e à tarde, e os comedouros completados com ração sempre que se fizesse necessārio.

Foram feitas três pesagens, uma no início do ex perimento, outra no 260 dia de idade das aves, e a última aos $47^{\circ}$ dias de idade, ou seja, no término do experimento.

A iluminação artificial foi efetuada de maneira que as aves tivessem 1 uz por 24 horas diárias durante todo o período experimental. 


\subsection{AS RAÇ̃ES EXPERIMENTAIS}

As rações foram balanceadas segundo as exigēncias apresentadas por SCOTT et alii (1973 e 1976). Os aditivos, tais como coccidiostático, coccidicida e estimulante de

crescimento foram adicionados às rações conforme especificações dos fabricantes.

Os resíduos sōlidos desidratados de efluente de biodigestor provenientes de esterco de aves matrizes e vacas em lactação, foram analisados no laboratório de bromatologia do Departamento de Zootecnia da Escola Superior de Agricultura "Luiz de Queiroz", e o aminograma feito no laboratório da FATEC Química Industrial S/A, em São Paulc. Os resultados dessas aná 1 ises são encontrados nas Tabelas 1 e 2 .

Os demais ingredientes foram analisados no labo ratório de Bromatologia do Departamento de Zootecnia da Escola Superior de Agricultura "Luiz de Queiroz" e no Laboratório da SUPRE MAIS - COMERCIO REPRESENTACAO DE PRODUTOS BIOQUIMICOS LTDA., e os resultados analíticos apresentados na Tabela 3 . 
Tabela 1 - Análise química dos resíduos sólidos desidràtados de efluente de biodigestor, fósforo disponível e energia metabolizāvel.

\begin{tabular}{|c|c|c|}
\hline \multirow[t]{2}{*}{ Parâmetros analisados } & \multicolumn{2}{|c|}{$\begin{array}{c}\text { Residuos sólidos desidratados } \\
\text { de efluente de biodigestor } \\
\text { oriundos de }\end{array}$} \\
\hline & Aves & Bovinos \\
\hline Matéria seca, $:$ & 91,74 & 94,73 \\
\hline Proteína bruta, : & 19,65 & 16,18 \\
\hline Fibra bruta, $\stackrel{\circ}{\circ}$ & 8,14 & 9,81 \\
\hline Extrato etēreo, $\stackrel{\circ}{0}$ & 1,70 & 1,60 \\
\hline Matēria mineral, : & 35,89 & 40,51 \\
\hline Extrativo não nitrogenado, $\%$ & 26,18 & 26,74 \\
\hline Cālcio, : & 2,535 & 1,58 \\
\hline Fósforo total, : & 1,160 & 0,97 \\
\hline Füsforo disponível, $:{ }^{(*)}$ & 0,386 & 0,323 \\
\hline Energia metabolizável, $\mathrm{kcal} / \mathrm{kg}^{(* *)}$ & 1300,00 & 1300,00 \\
\hline
\end{tabular}

* Valor estimado em 1/3 do fósforo total.

** Valor estimado por extrapolação. (ALIEN, 1980). 
Tabela 2 - Aminograma dos resỉduos sólidos desidratados de efluente de bio digestor.

\begin{tabular}{|c|c|c|}
\hline \multirow[t]{2}{*}{ Aminoäcidos } & \multicolumn{2}{|c|}{$\begin{array}{l}\text { Residuos sólidos desidratados } \\
\text { de efluente de biodigestor } \\
\text { oriundos de }\end{array}$} \\
\hline & Aves & Bovinos \\
\hline & $\frac{\circ}{0}$ & $\stackrel{\circ}{0}$ \\
\hline Lisina & 0,51 & 0,32 \\
\hline Histidina & 0,19 & 0,11 \\
\hline Arginina & 0,53 & 0,39 \\
\hline Ácido aspärtico & 0,94 & 0,94 \\
\hline Treonina & 0,66 & 0,53 \\
\hline Serina & 0,72 & 0,61 \\
\hline Ácido glutâmico & 0,96 & 0,90 \\
\hline Prolina & 0,78 & 0,52 \\
\hline Cistina & 0,13 & 0,05 \\
\hline Glïcina & 0,84 & 0,73 \\
\hline Alanina & 0,91 & 0,83 \\
\hline Valina & 0,74 & 0,51 \\
\hline Metionina & 0,05 & 0,09 \\
\hline Isoleucina & 0,57 & 0,41 \\
\hline Leucina & 1,02 & 0,76 \\
\hline Tirosina & 0,32 & 0,21 \\
\hline Fenilalanina & 0,57 & 0,40 \\
\hline Triptofano ${ }^{(*)}$ & 0,17 & 0,14 \\
\hline
\end{tabular}

* Valor calculado a partir de resíduo de fermentação. (ALLEN, 1980). 
.18.

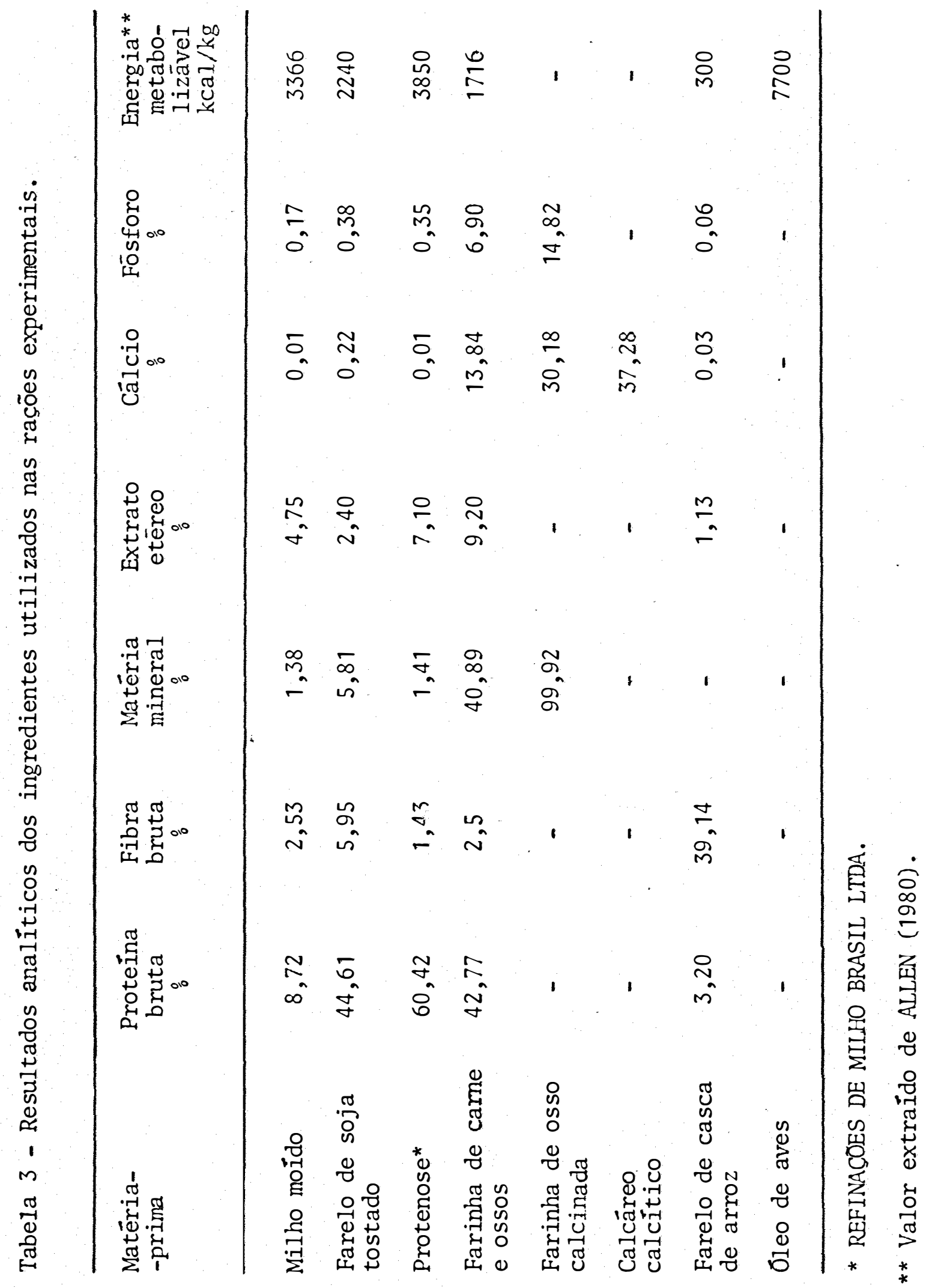


Foram utilizados dois tipos de raçoses: uma inicial (até 26 dias de idade) com $2900 \mathrm{kcal} / \mathrm{kg}$ de energia metabo lizável e $22 \%$ de proteína bruta, e uma final (do 27 a a 47 dia de idade) com $2970 \mathrm{kcal} / \mathrm{kg}$ de energia metabolizável e $20 \%$ de proteína bruta, segundo recomendações apresentadas por SCOTT et alii (1973 e 1976).

As rações deficientes em lisina e metionina receberam os aminoácidos em quantidades relativas ao teor energé tico, segundo recomendações de SCOTT et alii (1973 e 1976), sen do suplementadas aos níveis apresentados nos Quadros 1 e 2 .

As rações utilizadas no experimento foram:

- BASAL - ração testemunha.

- $A_{3}$ - ração com $3 \%$ de residuo sólido desidratado de efluente de biodigestor, proveniente de esterco de galinhas matrizes. - $A_{6}$ - ração com 6\% de residuo sólido desidratado de efluente de biodigestor, proveniente de esterco de galinhas matrizes.

- Ag - ração com 9\% de resíduo sólido desidratado de efluente de biodigestor, proveniente de esterco de galinhas matrizes.

- $B_{3}$ - ração com $3 \%$ de resíduo sólido desidratado de efluente de biodigestor, proveniente de esterco de vacas em lactação.

- $B_{6}$ - ração com 6\% de resíduo sólido desidratado de efluente de biodigestor, proveniente de esterco de vacas em lactação.

- Bg - ração com 9\% de resíduo sólido desidratado de efluente de biodigestor, proveniente de esterco de vacas em lactação. 
As composiçöes porcentuais e nutritivas das rações iniciais e finais são apresentadas nos Quadros 1 e 2 , e a composição dos suplementos mineral-vitamínico e aditivos é mos trada no Quadro 3.

As rações foram preparadas em misturador vertical de $300 \mathrm{~kg}$ de capacidade, pertencente ao Departamento de Zootecnia da Escola Superior de Agricultura "Luiz de Queiroz", utilizando-se das matérias-primas previamente analisadas. 
Quadro 1. - Composição porcentua] e nutritiva das raçoes iniciais.

\begin{tabular}{|c|c|c|c|c|c|c|c|}
\hline \multirow{2}{*}{ Ingredientes } & \multicolumn{7}{|c|}{ Raçōes experimentais, : } \\
\hline & BASAL & $A_{3}$ & $A_{6}$ & $A_{9}$ & $\mathrm{~B}_{3}$ & $\mathrm{~B}_{6}$ & $\mathrm{~B}_{9}$ \\
\hline Milho moído & 59,00 & 58,00 & 56,00 & 53,50 & 57,00 & 55,00 & 51,70 \\
\hline $\begin{array}{l}\text { Farelo de soja } \\
\text { tostado }\end{array}$ & 29,20 & 28,00 & 27,0 & 26,00 & 28,00 & 27,00 & 27,00 \\
\hline $\begin{array}{l}\text { Farinha de car } \\
\text { ne e ossos }\end{array}$ & 3,00 & 3,00 & 3,10 & 2,90 & 3,00 & 3,10 & 2,90 \\
\hline Protenose* & 4,10 & 4,20 & 4,20 & 4,50 & 4,50 & 4,70 & 4,50 \\
\hline $\begin{array}{l}\text { Farinha de os- } \\
\text { sos calcinada }\end{array}$ & 1,30 & 1,10 & 1,20 & 1,20 & 1,30 & 1,20 & 1,20 \\
\hline $\begin{array}{l}\text { Farelo de cas- } \\
\text { ca de arroz }\end{array}$ & 1,40 & 0,50 & 0 & 0 & 0,80 & 0 & 0 \\
\hline $\begin{array}{l}\text { Ingrediente } \\
\text { teste }\end{array}$ & 0 & 3,00 & 6,00 & 9,00 & 3,00 & 6,00 & 9,00 \\
\hline Sal moído & 0,30 & 0,30 & 0,30 & 0,30 & 0,30 & 0,30 & 0,30 \\
\hline $\begin{array}{l}\text { Suplemento mi- } \\
\text { neral-vitamíni } \\
\text { co e aditivos }\end{array}$ & 0,50 & 0,50 & 0,50 & 0,50 & 0,50 & 0,50 & 0,50 \\
\hline $\begin{array}{l}\text { Calcārio } \\
\text { cialcítico }\end{array}$ & 0,50 & 0,50 & 0,10 & 0 & 0,40 & 0,40 & 0,20 \\
\hline oleo de aves & 0,70 & 0,90 & 1,60 & 2,10 & 1,20 & 1,80 & 2,70 \\
\hline TOTAL & 100,00 & 100,00 & 100,00 & 100,00 & 100,00 & 100,00 & 100,00 \\
\hline $\begin{array}{l}\text { Proteína } \\
\text { bruta, }:\end{array}$ & 21,95 & 21,94 & 21,94 & 21,96 & 21,95 & 21,95 & 21,94 \\
\hline $\begin{array}{l}\text { Energia metabo- } \\
\text { lizavel, } \\
\mathrm{kcal} / \mathrm{kg}\end{array}$ & 2904 & 2900 & 2903 & 2882 & 2902 & 2904 & 2894 \\
\hline Cálcio, : & 1,062 & 1,074 & 1,044 & 1,053 & 1,069 & $i, 098$ & 1,042 \\
\hline $\begin{array}{l}\text { Fósforo dispo- } \\
\text { nível, }\end{array}$ & 0,472 & 0,475 & 0,482 & 0,478 & 0,480 & 0,479 & 0,474 \\
\hline Lisina, $\%$ & 1,100 & 1,100 & 1,100 & 1,100 & 1,100 & 1,100 & 1,100 \\
\hline Metionina, $\%$ & 0,440 & 0,440 & 0,440 & 0,440 & 0,440 & 0,440 & 0,440 \\
\hline
\end{tabular}

* REFINACOEES DE MILHO BRASIL LTDA. 
Quadro 2 - Composição porcentual e nutritiva das rações finais.

\begin{tabular}{|c|c|c|c|c|c|c|c|}
\hline \multirow{2}{*}{ Ingredientes } & \multicolumn{7}{|c|}{ Rações experimentais, $\%$} \\
\hline & BASAL & $\mathrm{A}_{3}$ & $A_{6}$ & $\mathrm{~A}_{9}$ & $\mathrm{~B}_{3}$ & $\mathrm{~B}_{6}$ & $\mathrm{~B}_{9}$ \\
\hline Milho moído & 59,00 & 58,00 & 57,00 & 55,00 & 57,00 & 56,00 & 53,70 \\
\hline $\begin{array}{l}\text { Farelo de soja } \\
\text { tostado }\end{array}$ & 29,15 & 28,00 & 27,00 & 26,00 & 28,00 & 27,00 & 26,00 \\
\hline $\begin{array}{l}\text { Farinha de car } \\
\text { ne e ossos }\end{array}$ & 2,00 & 2,30 & 2,00 & 2,00 & 3,00 & 3,00 & 3,00 \\
\hline Protenose* & 1,50 & 1,50 & 1,60 & 1,50 & 1,20 & 1,30 & 1,50 \\
\hline $\begin{array}{l}\text { Farinha de os- } \\
\text { so calcinada }\end{array}$ & 1,80 & 1,40 & 1,60 & 1,50 & 1,30 & 1,30 & 1,20 \\
\hline $\begin{array}{l}\text { Farelo de casca } \\
\text { de arroz }\end{array}$ & a 2,15 & 1,20 & 0,30 & 0 & 1,60 & 0,30 & 0 \\
\hline $\begin{array}{l}\text { Ingrediente } \\
\text { teste }\end{array}$ & 0 & 3,00 & 6,00 & 9,00 & 3,00 & 6,00 & 9,00 \\
\hline Sal moido & 0,30 & 0,30 & 0,30 & 0,30 & 0,30 & 0,30 & 0,30 \\
\hline $\begin{array}{l}\text { Suplemento mi- } \\
\text { neral-vitamíni } \\
\text { co e aditivos }\end{array}$ & 0,40 & 0,40 & 0,40 & 0,40 & 0,40 & 0,40 & 0,40 \\
\hline $\begin{array}{l}\text { Calcário } \\
\text { calcítico }\end{array}$ & 0,60 & 0,50 & 0,20 & 0 & 0,50 & 0,40 & 0,30 \\
\hline Oleo de aves & 3,10 & 3,40 & 3,60 & 4,30 & 3,70 & 4,00 & 4,60 \\
\hline TOTAL & 100,00 & 100,00 & 100,00 & 100,00 & 100,00 & 100,00 & 100,00 \\
\hline $\begin{array}{l}\text { Proteina } \\
\text { bruta, }:\end{array}$ & 19,95 & 20,03 & 19,99 & 19,89 & 19,99 & 19,95 & 19,90 \\
\hline $\begin{array}{l}\text { Energia metabo- } \\
\text { lizāvel, } \\
\mathrm{kcal} / \mathrm{kg}\end{array}$ & -2972 & 2978 & 2972 & 2972 & 2969 & 2975 & 2968 \\
\hline Cälcio, : & 1,111 & 1,068 & 1,048 & 1,018 & 1,106 & 1,114 & 1,092 \\
\hline $\begin{array}{l}\text { Fösforo dispo- } \\
\text { nível, } \frac{\circ}{0}\end{array}$ & 0,474 & 0,467 & 0,465 & 0,458 & 0,476 & 0,484 & 0,476 \\
\hline Lisina, : & 1,033 & 1,019 & 0,998 & 0,980 & 1,024 & 1,001 & 0,981 \\
\hline Metionina, $:$ & 0,400 & 0,400 & 0,400 & 0,400 & 0,400 & 0,400 & 0,400 \\
\hline
\end{tabular}

* REFINAÇOES DE MILHO BRASIL LTDA. 
Quadro 3 - Suplementação vitamínico-mineral e aditivos por kg de ração.

\begin{tabular}{|c|c|c|}
\hline & Inicial & Engorda \\
\hline Vitamina A & 10.000 U.I. & 8.000 U.I. \\
\hline Vitamina $D_{3}$ & 2.200 U.I. & 1.760 U.I. \\
\hline Vitamina $\mathrm{E}$ & 12 U.I. & 9,60 U.I. \\
\hline Vitamina $\mathrm{K}_{3}$ & $2,00 \mathrm{mg}$ & $1,60 \mathrm{mg}$ \\
\hline Vitamina $B_{1}$ & 2,00 mg & $1,60 \mathrm{mg}$ \\
\hline Vitamina $\mathrm{B}_{2}$ & $4,00 \mathrm{mg}$ & $3,20 \mathrm{mg}$ \\
\hline Vitamina $\mathrm{B}_{6}$ & $5,00 \mathrm{mg}$ & $4,00 \mathrm{mg}$ \\
\hline Vitamina $B_{12}$ & $10,00 \mathrm{mcg}$ & $8,00 \mathrm{mcg}$ \\
\hline Ácido nicotínico & $30,00 \mathrm{mg}$ & $24,00 \mathrm{mg}$ \\
\hline Ācido fólico & $1,00 \mathrm{mg}$ & $0,80 \mathrm{mg}$ \\
\hline Ácido pantotênico & $15,00 \mathrm{mg}$ & $12,00 \mathrm{mg}$ \\
\hline Biotina & $0,10 \mathrm{mg}$ & $0,08 \mathrm{mg}$ \\
\hline Manganês & $60,00 \mathrm{mg}$ & $48,00 \mathrm{mg}$ \\
\hline Ferro & $40,00 \mathrm{mg}$ & $32,00 \mathrm{mg}$ \\
\hline Cobre & $10,00 \mathrm{mg}$ & $8,00 \mathrm{mg}$ \\
\hline Zinco & $50,00 \mathrm{mg}$ & $40,00 \mathrm{mg}$ \\
\hline Selënio & $0,15 \mathrm{mg}$ & $0,12 \mathrm{mg}$ \\
\hline Iodo & $0,40 \mathrm{mg}$ & $0,32 \mathrm{mg}$ \\
\hline Nitrovin ${ }^{1}$ & $13,00 \mathrm{mg}$ & $13,00 \mathrm{mg}$ \\
\hline Nicrazin ${ }^{2}$ & $125,00 \mathrm{mg}$ & - \\
\hline Stenorol ${ }^{3}$ & - & $3,00 \mathrm{mg}$ \\
\hline Antioxidante & $120,00 \mathrm{mg}$ & $120,00 \mathrm{mg}$ \\
\hline
\end{tabular}

1 M. CASSAB COM. IND. LTDA.

2 MERCK SHARP DOHME

${ }^{3}$ QUIMIO S/A 


\subsection{DADOS COLETADOS}

\subsubsection{GANHO MÉDIO DE PESO}

As aves foram pesadas no início do experimento e no final de cada período de criação, ou seja, no primeiro dia, no 269 dia e no 479 dia, sendo todas as pesagens coletivas. Fo ram objeto de análise os ganhos de peso compreendidos entre 1 e 26,27 a 47 e 1 a 47 dias de idade das aves.

\subsubsection{CONSUMO MÉDIO DE RACÃO}

0 consumo médio de raçäo por parcela e por tratamento foi calculado a partir das conversões alimentares médias das parcelas e dos tratamentos, devidc à morte e descarte de animais no decorrer do período experimental, e são mostrados nas Tabelas 4,5 e 6 do Apêndice.

\subsubsection{MORTALIDADE}

A mortalidade era registrada no dia do evento, sendo as aves pesadas tão logo fosse constatada a morte e registrados os seus pesos. 


\subsubsection{CONVERSÃO ALIMENTAR MÉDIA}

Através do consumo de ração e do ganho de peso anotados durante cada período de criação, determinou-se as res pectivas conversões alimentares de cada unidade experimental, sendo, portanto, analisadas as conversões alimentares entre os dias 1 e 26,26 e 47 e 1 a 47 dias de idade das aves.

\subsection{DELINEAMENTO EXPERIMENTAL}

Foram utilizados 7 tratamentos com 4 repetições, submetidos a um delineamento inteiramente casualizado, segundo esquema de GOMES (1976), sendo as quatro repetições constituidas de dois lotes de machos e dois lotes de fêmeas, e a significância estatística verificada através do teste "F".

Os graus de liberdade para tratamentos foram de compostos com o objetivo de avaliar o desempenho das aves nas idades estudadas, quando submetidas à alimentação contendo resíduo sólido desidratado de efluente de biodigestor provenientes de estercos de galinhas matrizes e vacas em lactação, em niveis crescentes de incorporação às rações experimentais.

Em caso de significância estatística ao nível minimo de 5\% de probabilidade, as médias foram comparadas entre si pelo teste de Tukey. 
Foram verificadas as significâncias das equações de regressão ao nível de $5 \%$ de probabilidade, também pelo teste "F", e determinadas as equações de regressão. 


\section{RESULTADOS E DISCUSSÃO}

\subsection{GANHO MÉDIO DE PESO DO 10 AO 26ㅇ DIA DE IDADE}

0 Quadro 4 apresenta o ganho mëdio de peso das aves por tratamento, enquanto que a Tabela 7 do Apêndice apresenta o ganho médio de peso por parcela.

A análise de variância apresentada no Quadro 5 , apontou diferenças estatisticamente significativas tanto para ganho médio de peso entre rações como para ganho médio de peso entre sexos, porém a interação rações $x$ sexos não apresentou diferenças estatisticamente significativas. 0 desdobramento dos graus de liberdade de rações, mostrou diferenças estatisticamente significativas para níveis, o que não ocorreu para materiais, enquanto que a interação níveis $x$ materiais que foi estatisticamente significativa, mostrou diferenças estatistica- 
mente significativas para materiais dentro do nível 1 ( $3 \%$ ), ma teriais dentro do nível $2(6 \%)$ e materiais dentro do nivel 3 $(9 \%)$, bem como para níveis dentro do material proveniente do esterco de bovinos.

Quadro 4 - Ganho médio de peso (1 a 26 dias de idade).

\begin{tabular}{lcc}
\hline Rações & $\begin{array}{c}\text { Ganho médio de peso } \\
\mathrm{g}\end{array}$ & Indice relativo \\
\hline BASAL & 761 & 95,6 \\
$\mathrm{~A}_{3}$ & 773 & 98,0 \\
$\mathrm{~A}_{6}$ & 750 & 95,1 \\
$\mathrm{~A}_{9}$ & 750 & 95,1 \\
$\mathrm{~B}_{3}$ & 704 & 89,3 \\
$\mathrm{~B}_{6}$ & 788 & 100,0 \\
$\mathrm{~B}_{9}$ & 785 & 99,6 \\
\hline
\end{tabular}


Quadro 5 - Anälise de variância dos dados referentes ao ganho médio de pe so e conversão alimentar média, no período de 1 a 26 dias de $\underline{i}$ dade.

\begin{tabular}{|c|c|c|c|}
\hline \multirow{2}{*}{ C.V. } & \multirow{2}{*}{ G.L. } & \multicolumn{2}{|c|}{$\begin{array}{l}\text { Quadrados médios } \\
\text { de } 1 \text { a } 26 \text { dias de idade }\end{array}$} \\
\hline & & $\begin{array}{l}\text { Ganho mēdio } \\
\text { de peso }\end{array}$ & $\begin{array}{l}\text { Conversão ali- } \\
\text { mentar média }\end{array}$ \\
\hline Rações (R) & $(6)$ & $3281,85^{* *}$ & $0,0124 * *$ \\
\hline Basal $x$ Demais & 1 & 26,50 & $0,0262^{* *}$ \\
\hline Níveis $(\mathrm{N})$ & 2 & $2380,05^{*}$ & $0,0034^{*}$ \\
\hline Materiais $(M)$ & 1 & 21,80 & 0,0033 \\
\hline$N \times M$ & 2 & $7441,35^{\star *}$ & $0,0192 * *$ \\
\hline Sexos (S) & 1 & $64615,60^{* *}$ & $0,0195^{* *}$ \\
\hline$R \times S$ & 6 & 1412,05 & 0,0005 \\
\hline Resíduo & 14 & 558,29 & 0,0008 \\
\hline TOTAL & 27 & & \\
\hline Materiais/Nível 1 & 1 & $9389,30^{* *}$ & 0,0364 ** \\
\hline Materiais/Nível 2 & 1 & 2929., $18^{*}$ & 0,0006 \\
\hline Materiais/Nível 3 & 1 & $2585,87^{*}$ & $0,0045^{*}$ \\
\hline Nível/Est. galinhas & 2 & 703,95 & $0,0081^{* *}$ \\
\hline Linear & 1 & 1077,64 & $0,0162 * *$ \\
\hline Desvios & 1 & 330,26 & 0,00007 \\
\hline Níve1/Est. bovinos & 2 & $9117,45^{* *}$ & $0,0144^{* *}$ \\
\hline Linear & 1 & $13207,19^{* *}$ & $0,0171^{* *}$ \\
\hline Desvios & 1 & $5027,75^{* *}$ & $0,0117 * *$ \\
\hline $\begin{aligned} & * \mathrm{P}<0,05 \\
* * \mathrm{P} & <0,01\end{aligned}$ & & C.V. $=3,11 \%$ & C.V. $=1,60 \%$ \\
\hline
\end{tabular}


Pelos resultados da análise mostrada no Quadro 4 , observa-se que a ração $B_{3}$ apresentou valor de ganho médio de peso acentuadamente inferior aos das outras rações. Esse fa to fugindo ao esperado, não pôde ser justificado experimentalmente, apesar do valor encontrado não ter diferido estatistica camente das rações basal, $A_{6}$ e $A_{9}$, e diferido das outras. Porém, na tentativa de explicar o ocorrido, levantou-se a hipóte se que por ocasião da preparação das rações, quando sempre a ração $B_{3}$ foi a ültima a ser preparada, foi observado que o mi1ho moido que descia do silo apresentava uma granulometria menor, parecendo, portanto, ser diferente do milho utilizado nas demais rações. Essa suposição é feita, no sentido de que a for ma cônica do silo tenha sido responsável por essa diferença,

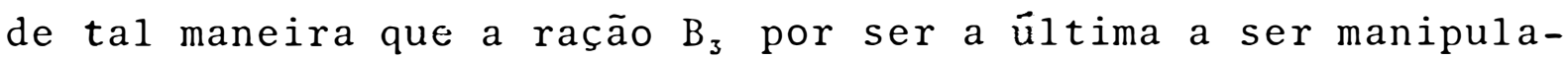
da, recebia uma grande proporção de fubá fino de milho podendo ter sido alterada a qualidade do milho utilizado em relação ao empregado nas outras rações.

Não se considerando a ração $B_{3}$ devido ao proble ma apresentado, pode ser observada uma tendência para pior ganho de peso quando aumentada a percentagem dos ingredientes teste, bem como melhor ganho de peso para as rações que continham resíduo sólido desidratado de efluente de biodigestor provindo do esterco de vacas em lactação, apesar de não terem sido observadas diferenças estatisticamente significativas.

A diferença estatisticamente significativa para sexos dispensa comentārios, uma vez que está comprovado universal- 
mente que em galinhas ocorre melhor ganho de peso para machos em relação às fêmeas.

Foram observados que os valores de ganho médio de peso referentes às aves alimentadas com rações contendo material oriundo do esterco de bovinos, ressalvando-se a ração $B_{3}$, foram estatisticamente maiores que os apresentados pelas $\underline{\text { a }}$ ves que receberam o material provindo de esterco de aves, apesar deste, na anālise laboratorial, apresentar maior teor protéico. Baseado nesse fato e no trabalho de YOSHIDA e HOSHII (1978) que sugeriram ser nulo o valor de energia metabolizàvel para o resíduo de fermentação oriundo do esterco de aves, o Au tor sugere que sejam realizadas pesquisas para verificação da energia metabolizāvel dos dois materiais, já que essas determi nações não foram o objetivo do presente trabalho. O valor da $\underline{\mathrm{e}}$ nergia metabolizável por quilo de ingrediente teste foi estima do no presente trabalho em $1300 \mathrm{kcal}$ por quilo.

A significância estatística observada para níveis dentro do material provindo do esterco de bovinos, ocorreu devido ao problema da ração $B_{3}$, uma vez que os valores de ganho médio de peso das aves alimentadas com as rações $B_{6}$ e $B_{9}$ não diferiram estatisticamente entre si, embora tenha sido observada uma tendência de menor ganho de peso quando aumentado o nível do ingrediente teste nas rações experimentais conforme descrito anteriormente. 


\subsection{CONVERsÃo ALIMENTAR MÉdia DO 10 AO 26ㅇ DiA DE IDADE}

No Quadro 6, são mostradas as conversões alimentares médias por tratamento, enquanto que na Tabela 8 do Apêndice são mostradas as conversões alimentares médias por parce$1 \mathrm{a}$.

A anâlise de variância mostrada tambēm no Quadro 5, apresentou resultados semelhantes aos anteriormente de $\underline{s}$ critos.

Foram observadas diferenças estatisticamente signi ficativas nas médias das conversões alimentares das aves alimentadas com as 7 rações experimentais, o que também ocórreu entre sexos, entre a ração basal quando comparada com as demais e para interação níveis $x$ materiais. As variações de mate rial dentro do nivel $1(3 \%)$, nivel dentro do material provindo de esterco de galinhas e nivel dentro do material provindo de esterco de bovinos, também apresentaram diferenças estatistica mente significativas, bem como, material dentro do nível 3 $(9 \%)$.

Da mesma forma que o observado para ganho médio de peso, as conversões alimentares médias das aves alimentadas com a ração $B_{3}$ não serão consideradas nessa discussão. 
Quadro 6 - Conversão alimentar mëdia (19 ao 26 @ dia de idade).

\begin{tabular}{|c|c|}
\hline Rações & $\begin{array}{c}\text { Conversão al imentar } \\
\text { média } \\
\mathrm{kg} / \mathrm{kg}\end{array}$ \\
\hline
\end{tabular}

\begin{tabular}{lcc}
\hline BASAL & 1,65 & 100,0 \\
$\mathrm{~A}_{3}$ & 1,68 & 98,2 \\
$\mathrm{~A}_{6}$ & 1,72 & 95,8 \\
$\mathrm{~A}_{9}$ & 1,77 & 92,8 \\
$\mathrm{~B}_{3}$ & 1,81 & 90,4 \\
$\mathrm{~B}_{6}$ & 1,70 & 97,0 \\
$\mathrm{~B}_{9}$ & 1,72 & 95,8 \\
\hline
\end{tabular}

As conversões alimentares médias das aves alimentadas com as rações experimentais, apresentaram diferenças estatisticamente significativas como mostra o Gráfico 2, poden do-se observar que $\vec{a}$ medida que se aumentou o nível do ingrediente teste nas rações, a conversão alimentar média piorou, sendo a ração basal a que apresentou melhor conversão alimentar. Essa observação aliada ao fato de que a conversão alimentar das aves alimentadas com a ração basal, quando comparada com a média das conversões das demais rações, foi estatisticamente melhor, sugerindo que a ração basal era de melhor quali- 


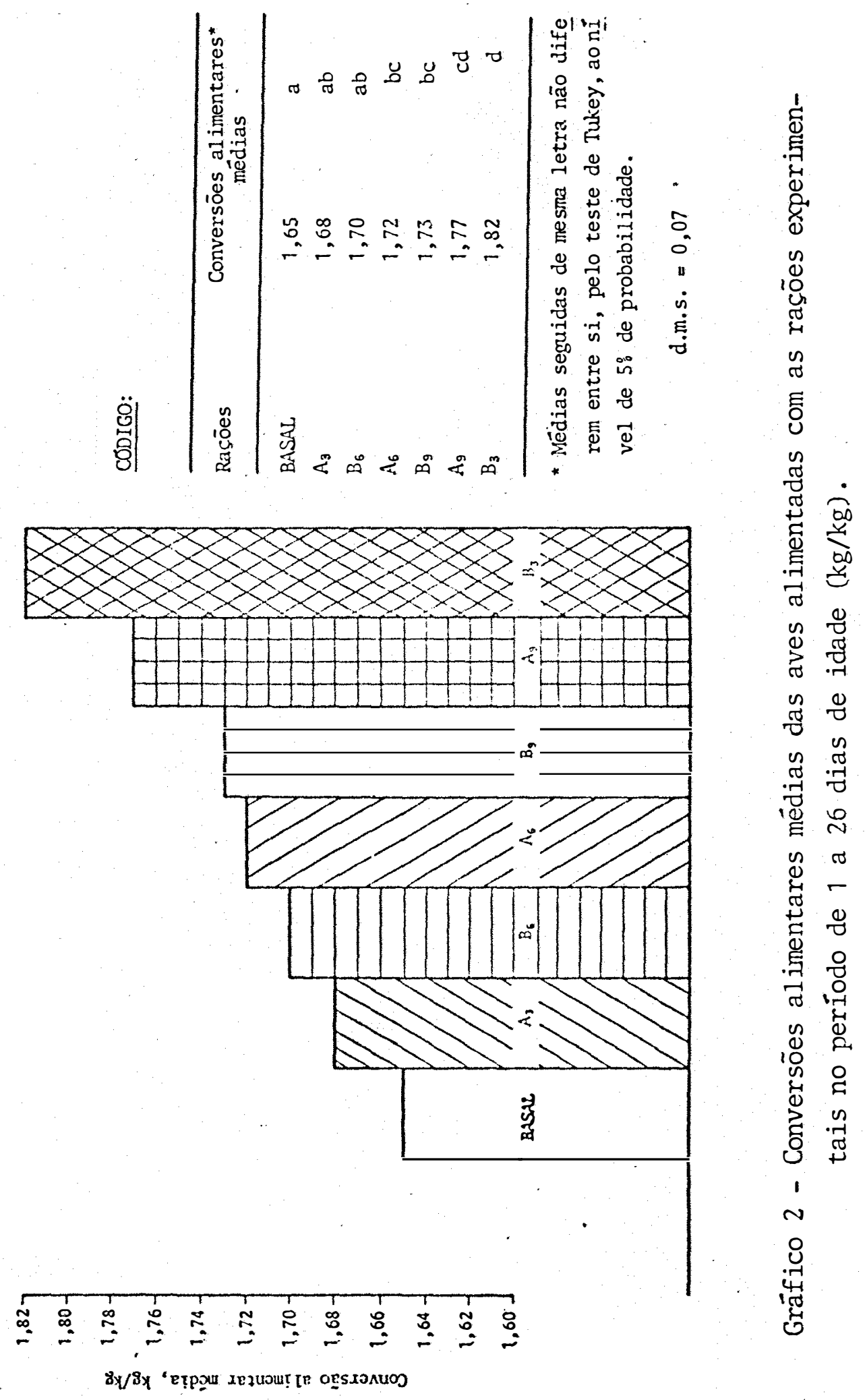


dade nutritiva, embora não tivesse diferido estatisticamente das médias das conversões alimentares das rações $A_{3}$ e $B_{6}$.

Apesar de não terem sido observadas diferenças estatisticamente significativas para materiais dentro do nível $2(6 \%)$, verificou-se tendência de superioridade nas médias de conversão alimentar das aves alimentadas com o material proveniente do esterco de bovinos em relação às aves alimentadas com o provindo do esterco de aves. Por outro lado, ao nivel de inclusão de $9 \%$ do ingrediente teste, as diferenças observadas en tre os valores de conversões alimentares das aves alimentadas com material oriundo de esterco de bovinos, foi estatisticamen te melhor do que as observadas com as aves alimentadas com o material provindo de esterco de aves.

Confirmando a tendência observada para um desem penho decrescente à medida do aumento dos ingredientes teste $\underline{\mathrm{u}}$ utilizados nas rações experimentais, verificou-se que as conversões alimentares das aves alimentadas com rações contendo $9 \%$ de inclusão do material oriundo do esterco de aves, foi estatisticamente inferior às aves alimentadas com rações contendo 3 e $6 \%$ de inclusão. Já para o material provindo do esterco de bovinos, embora não tenha sido verificada diferença estatis ticamente significativa entre as conversões alimentares médias das aves alimentadas com as rações $B_{6}$ e $B_{9}$, observou-se uma $1 \underline{i}$ geira superioridade da conversão alimentar média das aves alimentadas com ração $B_{6}$ em relação à ração $B_{9}$. A regularidade do desempenho decrescente quando observado o material oriundo do 
esterco de aves, é determinada por uma regressão linear estatisticamente significativa para as conversões alimentares das aves alimentadas com rações contendo os três níveis de inclusão do referido material (Gráfico 3). 


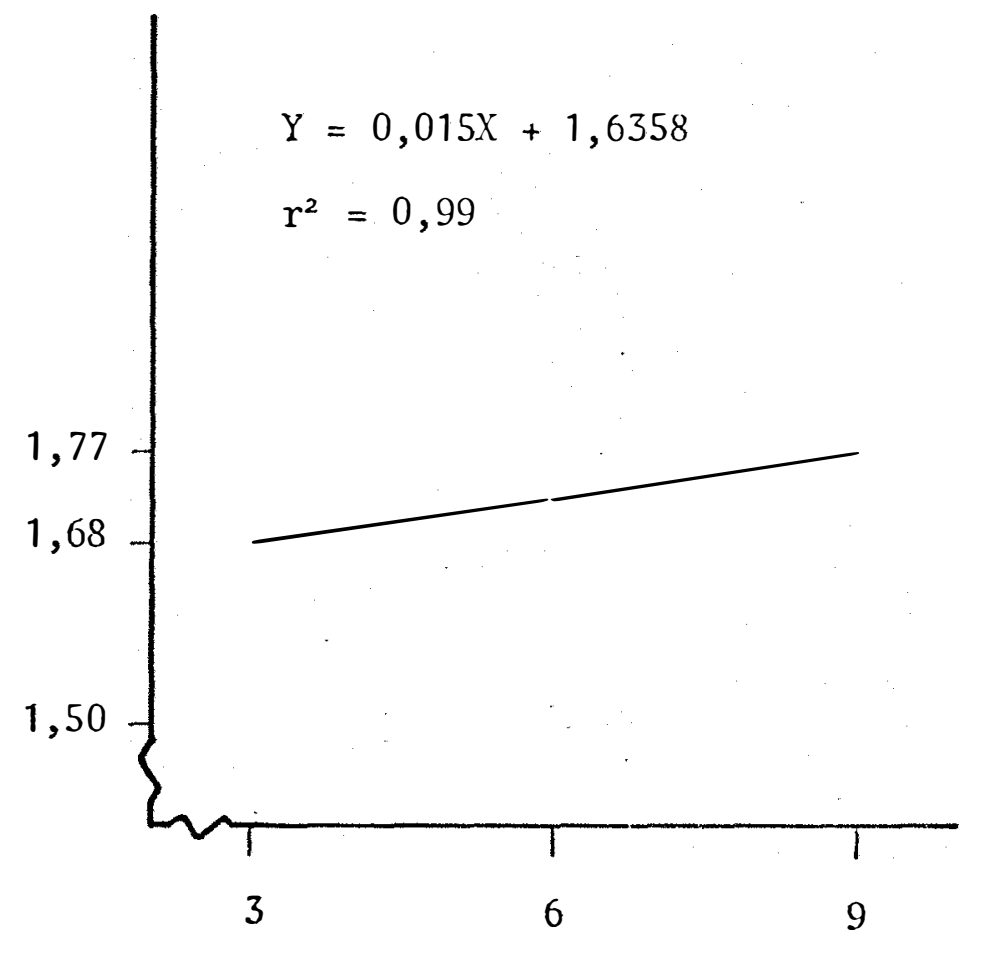

Gráfico 3 - Equação de regressão linear e coeficiente de correlação para conver são alimentar média das aves quando verificado níveis dentro de resíduo sólido desidratado de efluen te de biodigestor, oriundo de esterco de galinhas matrizes. 


\subsection{Ganho médio de peso e CONVERsão alimentar mé ia para OS PERIODOS COMPREENDIDOS ENTRE OS DIAS 27 A 47 E 1 A 47 DO EXPERIMENTO}

No segundo período de criação, bem como, no período total de criação do experimento, de uma maneira geral, não verificou-se diferenças estatisticamente significativas entre os parâmetros analisados, como pode ser observado nos Quadros 7 e 8 das análises de variância. Observou-se apenas as diferen ças estatisticamente significativas para ganho médio de peso entre sexos em ambos os perĩodos, o que já era esperado (Tabelas 9 e 10, Apêndice).

Embora não tenham sido observadas diferenças estą tisticamente significativas nos ganhos médios de peso e conver sões alimentares médias nos dois períodos de criação acima men cionados, pela análise dos Quadros 10 e 11 , verificou-se que as maiores diferenças entr os ganhos médios de peso dos dois períodos foram de 133 gramas (27 a 47 dias) e 155 gramas ( 1 a 47 dias), entre os tratamentos que recebera, as rações $A_{3}$ e $A_{6}$, - que pareceu ser elevado. Todavia, apesar das diferenças apre sentadas não terem sido estatisticamente significativas $(P<0,05)$ para este parâmetros, o "F" calculado se aproximou do "F" tabe lado, fato que poderia sugerir uma diferença estatisticamente significativa para um nível de um pouco mais elevado que o de 5\%, sem, no entanto, ser encontrada uma justificativa bio-expe rimental para o ocorrido, uma vez que o menor ganho médio de 
Quadro 7 - Anẩise de variância dos dados referentes a ganho médio de peso e conversão alimentar mëdia, no período de 27 a 47 dias de idade das aves.

\begin{tabular}{|c|c|c|c|c|}
\hline \multirow{2}{*}{ C.V. } & \multirow{2}{*}{ G.L. } & & \multicolumn{2}{|c|}{$\begin{array}{c}\text { Quadrados médios } \\
\text { ( } 27 \text { a } 47 \text { dias de idade) }\end{array}$} \\
\hline & & & $\begin{array}{l}\text { Ganho médio } \\
\text { de peso }\end{array}$ & $\begin{array}{l}\text { Conversão ali- } \\
\text { mentar média }\end{array}$ \\
\hline Rações (R) & $(6)$ & & 0,00733 & 0,044581 \\
\hline Basal $x$ Demais & 1 & & 0,00300 & 0,019286 \\
\hline Niveis (N) & 2 & & 0,01250 & 0,073913 \\
\hline Materiais $(M)$ & 1 & & 0,00300 & 0,014017 \\
\hline $\mathrm{N} \times \mathrm{M}$ & 2 & & 0,00650 & 0,040545 \\
\hline Sexos (S) & 1 & & $0, \dot{5} 6000$ ** & 0,000009 \\
\hline$R \times S$ & 6 & & 0,01050 & 0,049796 \\
\hline Resíduo & 14 & & 0,00686 & 0,030182 \\
\hline TOTAL & 27 & & & \\
\hline Materiais/nível 1 & 1 & & 0,00100 & 0,000113 \\
\hline Materiais/nível 2 & 1 & & 0,01600 & 0,092450 \\
\hline Materiais/nivel 3 & 1 & & 0,000003 & 0,007813 \\
\hline Nível/Est. galinhas & 2 & & 0,01751 & 0,097358 \\
\hline Linear & & 1 & 0,00769 & 0,014450 \\
\hline Desvios & & 1 & 0,02734 & $0,180267^{*}$ \\
\hline Nível/Est. bovinos & 2 & & 0,00149 & 0,019733 \\
\hline Linear & & 1 & 0,00296 & 0,039200 \\
\hline Desvios & & 1 & 0,00001 & 0,000267 \\
\hline $\begin{array}{rl}* & P<0,05 \\
* * & P<0,01\end{array}$ & & & C.V. $=7,07 \%$ & C.V. $=7,7 \%$ \\
\hline
\end{tabular}


Quadro 8 - Análise de variância dos dados referentes a ganho médio de peso e conversão alimentar miëdia, no período de 1 a 47 dias de idade das aves.

\begin{tabular}{|c|c|c|c|c|}
\hline \multirow{2}{*}{ C.V. } & \multirow{2}{*}{ G.L. } & & \multicolumn{2}{|c|}{$\begin{array}{l}\text { Quadrados médios } \\
\text { (1 a } 47 \text { dias de idade) }\end{array}$} \\
\hline & & & $\begin{array}{l}\text { Ganho médio } \\
\text { de peso }\end{array}$ & $\begin{array}{l}\text { Conversão ali- } \\
\text { mentar mëdia }\end{array}$ \\
\hline Rações (R) & (6) & & 0,010667 & 0,0145483 \\
\hline Basal $x$ Demais & 1 & & 0,004002 & 0,0342900 \\
\hline Niveis (N) & 2 & & 0,004265 & 0,0118650 \\
\hline Materiais (M) & 1 & & 0,003553 & 0,0004170 \\
\hline $\mathrm{N} \times \mathrm{M}$ & 2 & & 0,023958 & 0,0144265 \\
\hline Sexos (S) & 1 & & $1,006245^{* *}$ & 0,0041330 \\
\hline$R \times S$ & 6 & & 0,015806 & 0,0118945 \\
\hline Resĩduo & 14 & & 0,007358 & 0,0091783 \\
\hline TOTAL & 27 & & & \\
\hline Materiais/nível 1 & 1 & & 0,0165ó2 & 0,0078125 \\
\hline Materiais/nível 2 & 1 & & 0,032131 & 0,0210125 \\
\hline Materiais/nível 3 & 1 & & 0,002775 & 0,0004500 \\
\hline Nivel/Est. galinhas & 2 & & 0,024105 & 0,0240583 \\
\hline Linear & & 1 & 0,014535 & 0,0136125 \\
\hline Desvios & & 1 & 0,033675 & 0,0345042 \\
\hline Nỉvel/Est. bovinos & 2 & & 0,004119 & 0,0022333 \\
\hline Linear & & 1 & 0,003698 & 0,0024500 \\
\hline Desvios & & 1 & 0,004538 & 0,0020167 \\
\hline $\begin{array}{rl}* & P<0,05 \\
* * & P<0,01\end{array}$ & & & $C . V .=4,44 \%$ & $C . V .=4,71 \%$ \\
\hline
\end{tabular}


Quadro 10 - Ganho médio de peso (27 a 47 dias de idade).

\begin{tabular}{lcc}
\hline RACOES & $\begin{array}{c}\text { GANHO MEDIO DE PESO } \\
\mathrm{kg}\end{array}$ & \begin{tabular}{c} 
INDICE \\
REIATIVO \\
\hline Basal
\end{tabular} \\
$\mathrm{A}_{3}$ & 1,198 & 98 \\
$\mathrm{~A}_{6}$ & 1,021 & 100 \\
$\mathrm{~A}_{9}$ & 1,088 & 89 \\
$\mathrm{~B}_{3}$ & 1,159 & 94 \\
$\mathrm{~B}_{6}$ & 1,198 & 98 \\
$\mathrm{~B}_{9}$ & 1,177 & 96 \\
\hline
\end{tabular}


.42 .

Quadro 11 - Ganho médio de peso ( 1 a 47 dias de idade).

\begin{tabular}{|c|c|c|}
\hline RAÇOES & $\begin{array}{c}\text { GANHO MEDIO LE PESO } \\
\mathrm{kg}\end{array}$ & 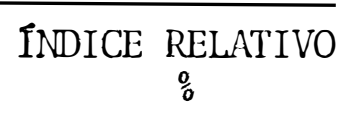 \\
\hline Basal & 1,960 & 98 \\
\hline $\mathrm{A}_{3}$ & $1,993$. & 100 \\
\hline$A_{6}$ & 1,838 & 92 \\
\hline$A_{9}$ & 1,908 & 95 \\
\hline $\mathrm{B}_{3}$ & 1,902 & 95 \\
\hline $\mathrm{B}_{6}$ & 1,965 & 98 \\
\hline $\mathrm{B}_{9}$ & 1,945 & 97 \\
\hline
\end{tabular}


.43.

Quadro 12 - Conversão alimentar média (27 a 47 dia de idade).

\begin{tabular}{lcc}
\hline RACOES & $\begin{array}{c}\text { CONVERSAO ALINIENTAR MEDIA } \\
\mathrm{kg} / \mathrm{kg}\end{array}$ & $\begin{array}{c}\text { INDICE: RELATIVO } \\
\frac{0}{0}\end{array}$ \\
\hline Basal & 2,19 & 98 \\
$\mathrm{~A}_{3}$ & 2,16 & 100 \\
$\mathrm{~A}_{6}$ & 2,46 & 86 \\
$\mathrm{~A}_{9}$ & 2,24 & 96 \\
$\mathrm{~B}_{3}$ & 2,17 & 99 \\
$\mathrm{~B}_{6}$ & 2,25 & 96 \\
$\mathrm{~B}_{9}$ & 2,31 & 93 \\
\hline
\end{tabular}


Quadro 13 - Conversão alimentar média (10 a 479 dia de idade).

\begin{tabular}{lcc}
\hline RAÇOES & $\begin{array}{c}\text { CONVERSAO ALIMENTAR MEDIA } \\
\mathrm{kg} / \mathrm{kg}\end{array}$ & $\begin{array}{c}\text { INDICE RELATIVO } \\
\frac{0}{0}\end{array}$ \\
\hline Basal & 1,95 & 100 \\
$\mathrm{~A}_{3}$ & 1,97 & 99 \\
$\mathrm{~A}_{6}$ & 2,13 & 90 \\
$\mathrm{~A}_{9}$ & 2,05 & 94 \\
$\mathrm{~B}_{3}$ & 2,03 & 95 \\
$\mathrm{~B}_{6}$ & 2,02 & 96 \\
$\mathrm{~B}_{9}$ & 2,07 & 93 \\
\hline
\end{tabular}


peso para as aves que receberam a ração $A_{6}$, deve-se a um ganho de peso relativamente baixo de uma das parcelas, o que pode ser observado nas Tabelas 9 e 10 do Apêndice. Os dados referentes a conversão alimentar com os respectivos índices relativos dos dois períodos, pode ser visto nos Quadros 12 e 13, e as conver sões alimentares por parcela nas Tabelas 11 e 12 do Apêndice. Os dados referentes à mortalidade durante a fase experimental dentro dos tratamentos utilizados, são mostrados no Quadro 9 do Apêndice. A alta mortalidade registrada nos tratamentos que receberam as rações Basal e $A_{3}$, deveu-se em grande parte a problemas acidentais provocados por ratos. Porém, na impossibilidade de precisar quanto, os dados aparecem por inteiro, como sendo de causa desconhecida. 


\section{CONCLUSÕES}

Nas condiçōes experimentais do presente traba1ho, a anâlise dos dados obtidos permitiu concluir que:

- Os resíduos sōlidos desidratados de efluente de biodigestor oriundos de estercos de galinhas matrizes e vacas em lactação, são viáveis de serem utilizados na alimentação de frango de corte, em níveis de incorporação até $6 \%$, uma vez que o aumento acima desse nível mostrou tendência em afetar negativamente o desempenho das aves experimentais. Entretanto, as diferenças nos parâmetros analisados não foram estatisticamente significativas.

- A utilização dos referidos resíduos promoveu melhor desempenho das aves, no segundo período de criação a 47 dias de idade). 
- Foi observada tendência de superioridade no desempenho das aves experimentais alimentadas com o material provindo do esterco de bovinos em comparação ao do de galinhas matrizes. 


\section{LITERATURA CITADA}

ALLEN, R.D., 1980. Ingredient Analysis Table: 1980 Edition. Feedstuffs. Minneapolis, 52(30): 23-30.

AZEVEDO FILHO, A.J.B.V. e F.R. BELO, 1984. Avaliação de A1ternativas Energéticas: O Gás metano - Biogās - Como Substituto dos Combustíveis Convencionais na Agricultura. [A- presentado à Conferência Latinoamericana de Economia Agrícola, Piracicaba, SP, 1984].

GOMES, F.P., 1973. Curso de Estatística Experimental. 7.ed., Piracicaba, Livraria Nobel S/A, 430p.

SCOTT, M.L.; M.C. NESHEIM e R.J. YOUNG, 1973. Alimentaciōn de Las Aves. Barcelona, Ediciones GEA. 507p. 
SCOTT, M.L.; M.C. NESHEIM e R.J. YOUNG, 1976. Nutrition of the Chicken. 2.ed., New York, M.L. SCOTT \& Associates. 555p.

SEX-SEPARATE broiler growing demands skilled management. 1983. Poultry Digest. Mount Morris, 42(496): 290-292.

SILVA, N.A., 1980. Brasil Elege Modelo Chinês para o Campo. Agricultura. Rio de Janeiro, (66): 36-37.

SILVA, N.A., 1984. Comunicação Pessoal.

YOSHIDA, M. e H. HOSHII, 1979. Nutritive value of Residue of Methane Fermentation From Excreta of Domestic Animals and Poultry. Nutrition Abstracts and Reviews, Farnhain Royal, $\underline{49}(1): 10$. 
.50 .

7. APÉNDICE 
Tabela 4 - Consumo médio de ração ( 1 a 26 dias), kg.

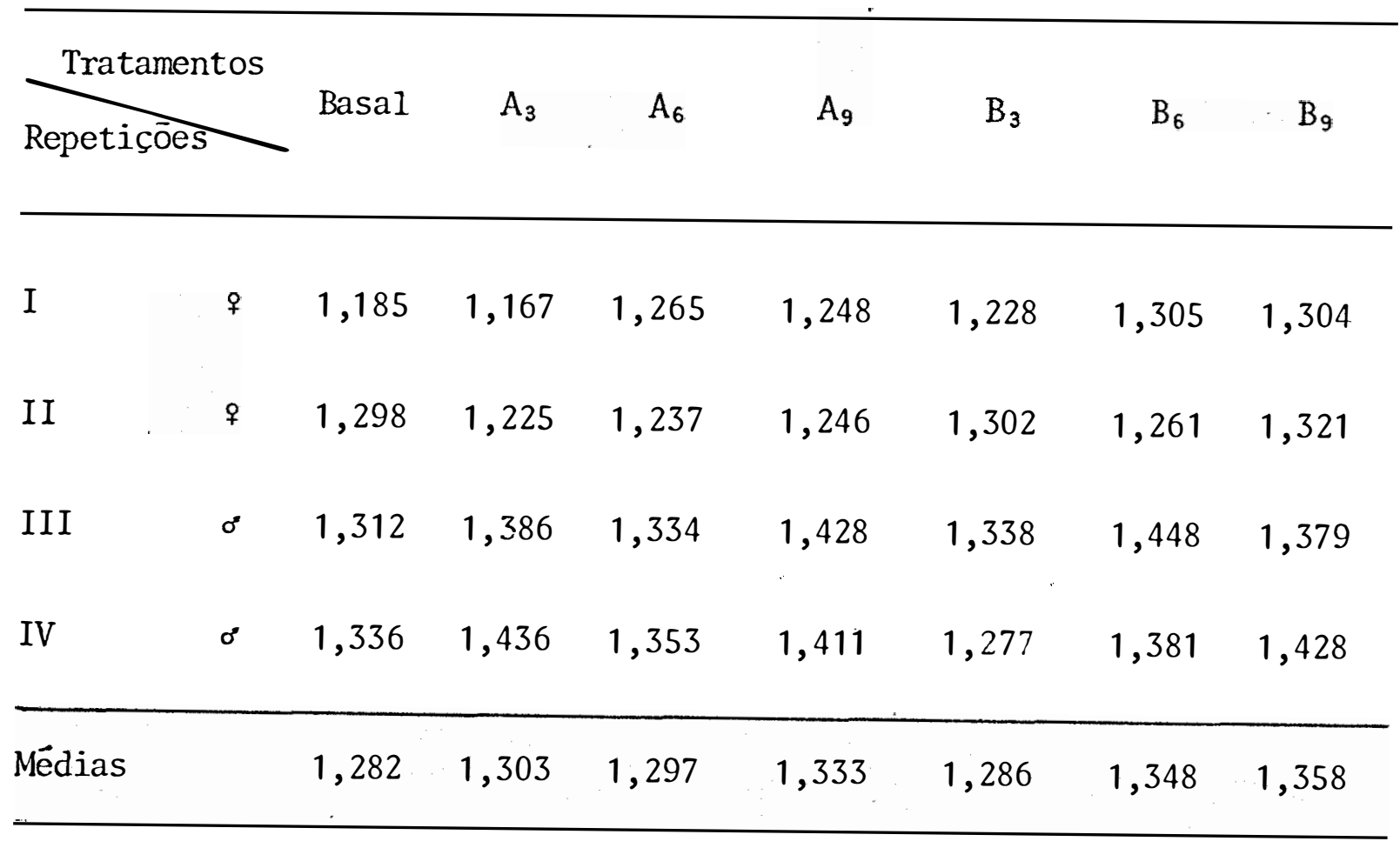


Tabela 5 - Consumo médio de ração (27 a 47 dias), kg:

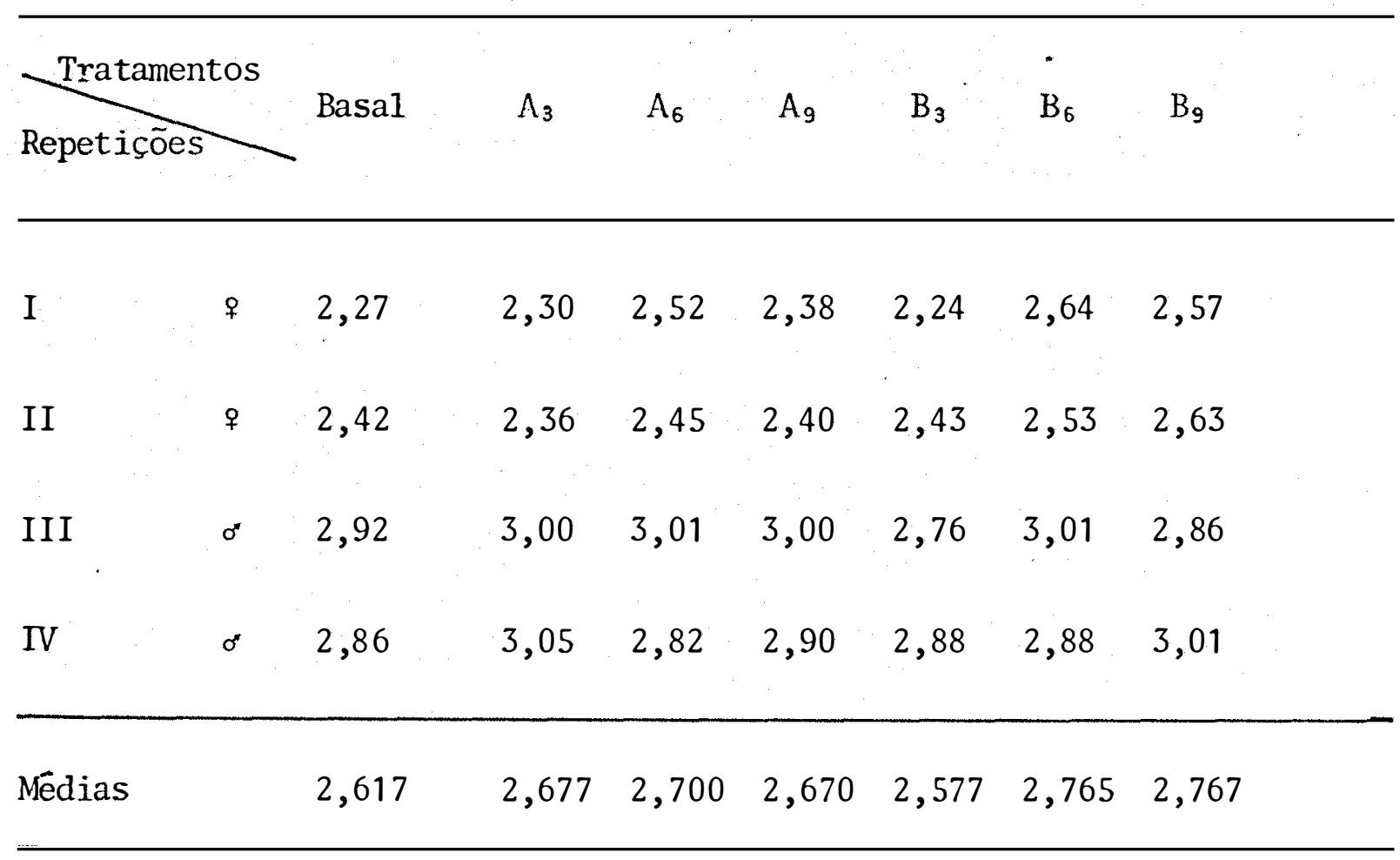


Tabela 6 - Consumo médio de ração ( 1 a 47 dias de idade).

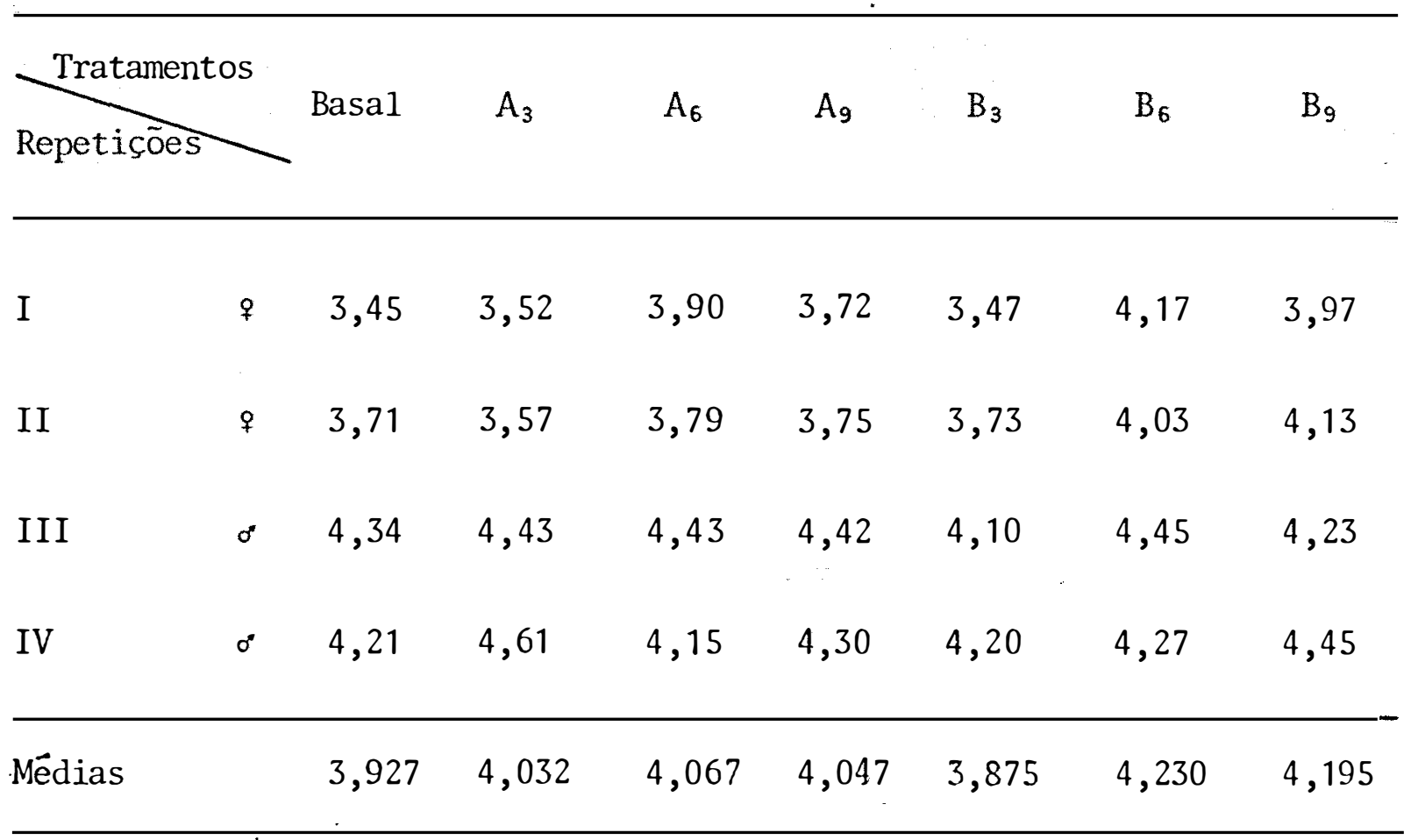


.54 .

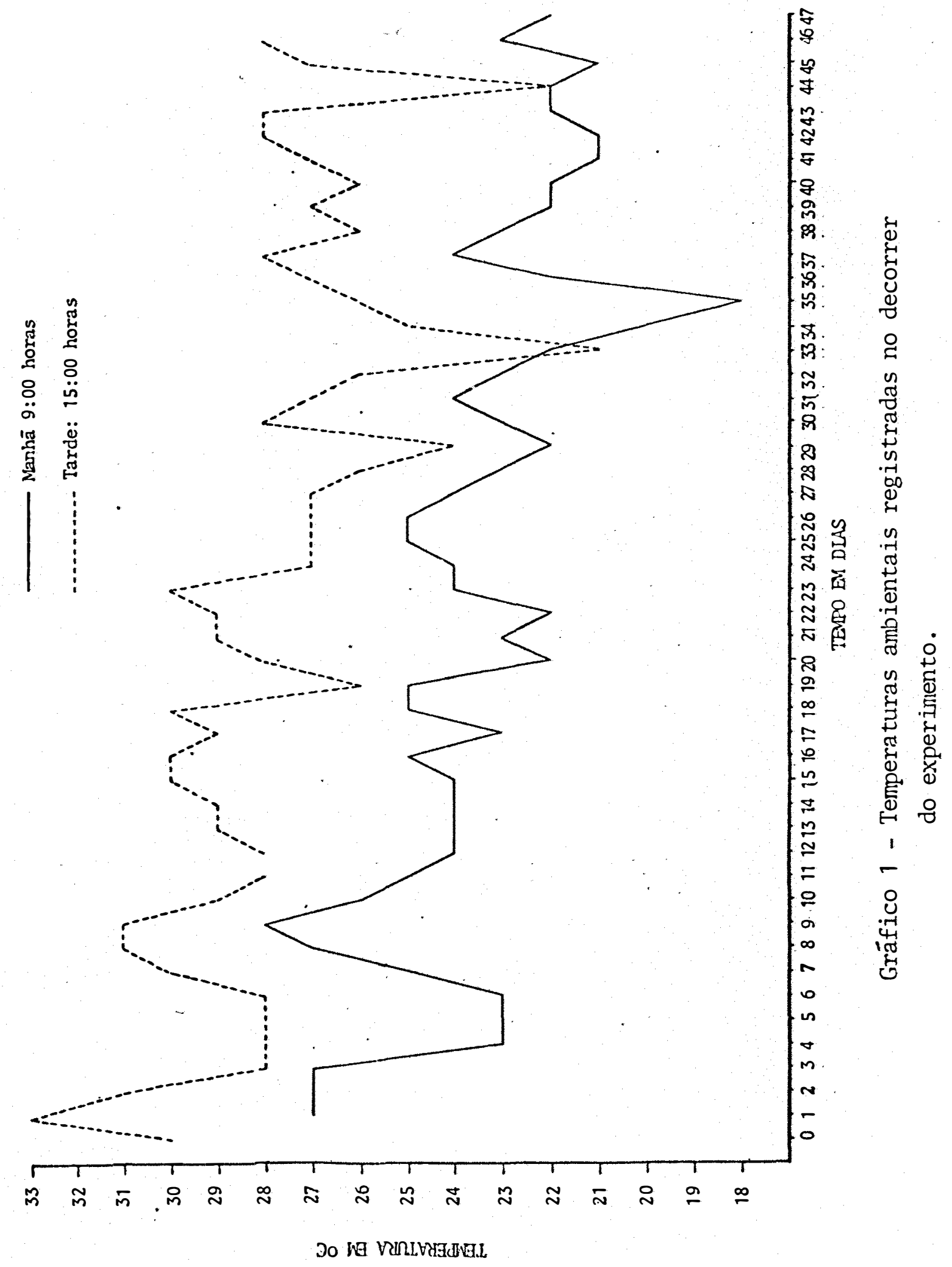


Tabela 7 - Ganho medio de peso (1 a 26 dias de idade), $\mathrm{g}$.

\begin{tabular}{|c|c|c|c|c|c|c|c|c|}
\hline$\overbrace{\text { Repetiçôes }}^{\text {Tratament }}$ & & Basal & $\mathrm{A}_{3}$ & $A_{6}$ & $A_{9}$ & $\mathrm{~B}_{3}$ & $B_{6}$ & $\mathrm{~B}_{9}$ \\
\hline I & $q$ & 692,69 & 675,38 & 737,69 & 693,46 & 654,62 & 751,92 & 739,61 \\
\hline II & $q$ & 710,39 & 716,16 & 703,07 & 694,23 & 709,62 & 725,38 & 752,69 \\
\hline III & $\sigma^{\circ}$ & 810,00 & 856,54 & 771,15 & 832,31 & 748,39 & 863,46 & 813,84 \\
\hline IV & $0^{\circ}$ & 833,46 & 844,77 & 790,00 & 780,00 & 706,15 & 814,23 & 837,69 \\
\hline Médias & & 761,63 & 773,21 & 750,47 & 750,00 & 704,69 & 788,74 & 785,95 \\
\hline
\end{tabular}


Tabela 8 - Conversão alimentar média (1 a 26 dias de idade), kg/kg.

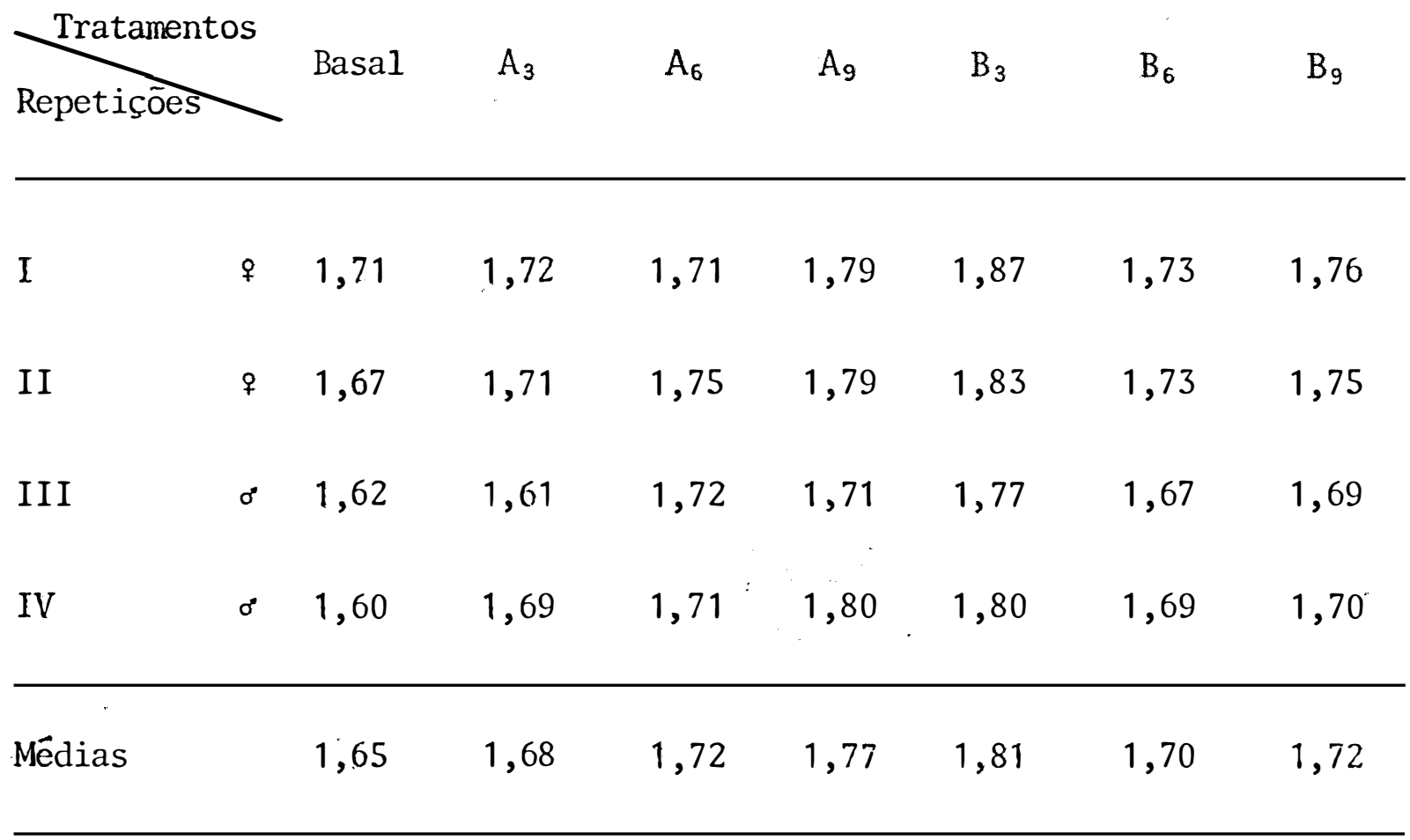


Tabela 9 - Ganho mëdio de peso (27 a 47 dias de idade), $\mathrm{kg}$.

\begin{tabular}{|c|c|c|c|c|c|c|}
\hline Repetições & Basal & $A_{3}$ & $A_{6}$ & $A_{9}$ & $\mathrm{~B}_{3}$ & $B_{6}$ \\
\hline
\end{tabular}

\begin{tabular}{|c|c|c|c|c|c|c|c|c|}
\hline I & $q$ & 1,030 & 1,053 & 1,065 & 0,965 & 1,015 & 1,026 & 0,998 \\
\hline II & $q$ & 1,042 & 1,061 & 1,054 & 0,994 & 1,077 & 0,999 & 1,047 \\
\hline III & $0^{\circ}$ & 1,342 & 1,376 & 0,921 & 1,346 & 1,296 & 1,361 & 1,242 \\
\hline IV & $0^{\circ}$ & 1,380 & 1,394 & 1,315 & 1,331 & 1,407 & 1,323 & 1,354 \\
\hline Médias & & 1,198 & 1,221 & 1,088 & 1,159 & 1,198 & 1,177 & 1,160 \\
\hline
\end{tabular}


Tabela 10 - Ganho médio de peso ( 1 a 47 dias de idade), $\mathrm{kg}$.

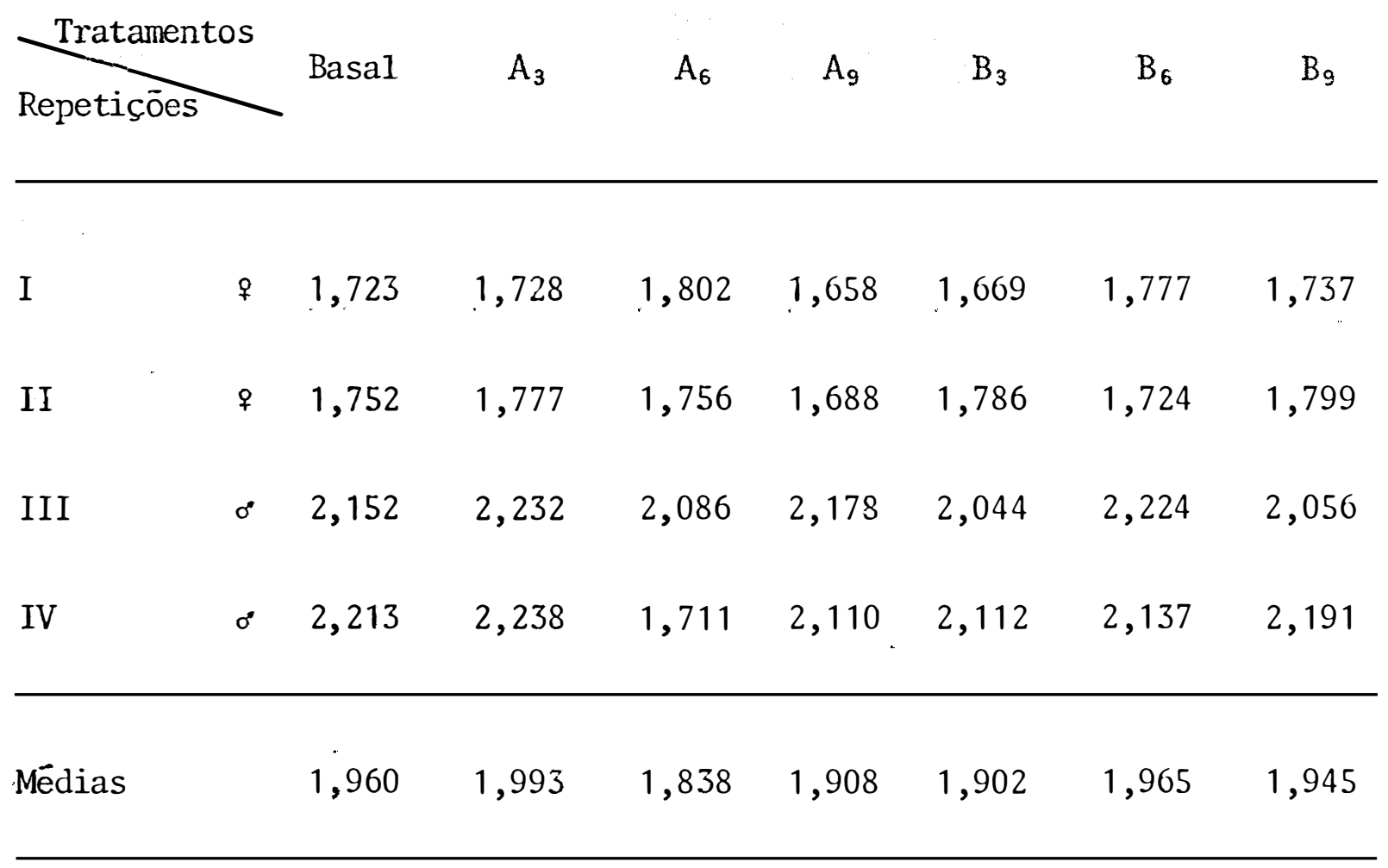


Tabela 11 - Conversão alimentar média (27 a 47 dias de idade), kg/kg.

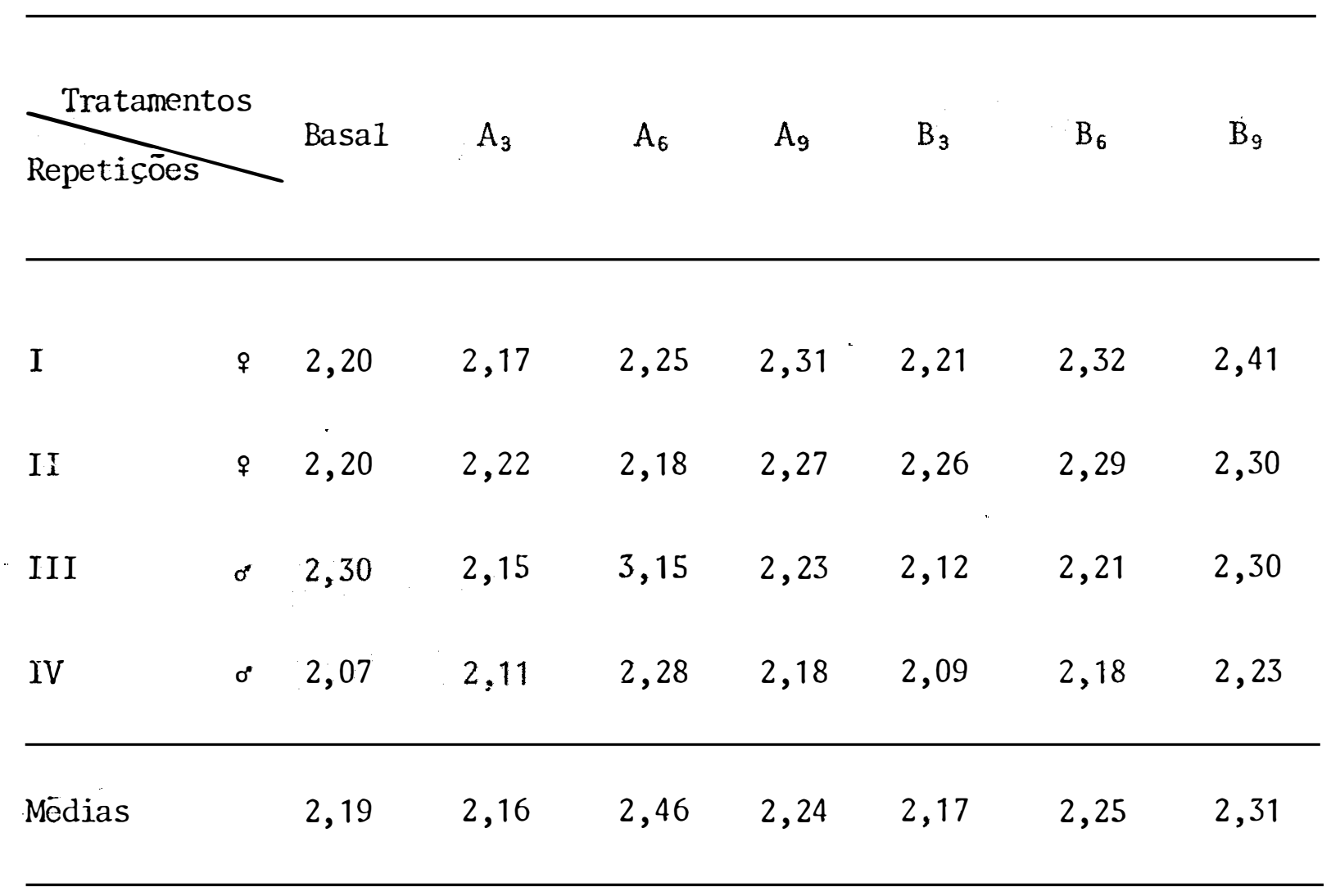


Tabela 12 - Conversão alimentar média ( 1 a 47 dias de idade), $\mathrm{kg} / \mathrm{kg}$.

\begin{tabular}{|c|c|c|c|c|c|c|c|c|}
\hline$\underbrace{\text { Tratamento }}_{\text {Repetiçôes }}$ & & Basal & $A_{3}$ & $A_{6}$ & $A_{9}$ & $\mathrm{~B}_{3}$ & $B_{6}$ & $\mathrm{~B}_{9}$ \\
\hline I & $q$ & 2,00 & 2,00 & 2,03 & 2,09 & 2,08 & 2,06 & 2,13 \\
\hline II & $q$ & 1,98 & 2,01 & 2,01 & 2,07 & 2,09 & 2,05 & 2,07 \\
\hline III & $0^{\circ}$ & 1,92 & 1,94 & 2,49 & 2,03 & 2,00 & 2,00 & 2,06 \\
\hline IV & $\sigma^{\circ}$ & 1,90 & 1,95 & 1,99 & 2,04 & 1,98 & 2,00 & 2,03 \\
\hline Médias & & 1,95 & 1,97 & 2,13 & 2,05 & 2,03 & 2,02 & 2,07 \\
\hline
\end{tabular}


Quadro 9 - Mortalidade durante os 47 dias do experimento em percentagem, por tratamento.

\begin{tabular}{lllllllll}
\hline & Basal & $A_{3}$ & $A_{6}$ & $A_{9}$ & $B_{3}$ & $B_{6}$ & $B_{9}$ \\
\hline Mortalidade: & 5,7 & 10,5 & 0,96 & 2,88 & 0,96 & 0,96 & 0,96 \\
\hline
\end{tabular}

